\title{
HISTORIA, TERROR Y SIMULACIÓN EN RAMOS MEJÍA E INGENIEROS
}

\author{
Sebastián Assaf \\ Universidad Nacional de Rosario \\ (Argentina) \\ sebas_assaf@hotmail.com
}

\begin{abstract}
Resumen: El llamado "positivismo argentino" posee, en sus dos figuras mayores, un marcado perfil ensayístico. En Ramos Mejía como Ingenieros, aunque particularmente en el primero, subsiste algo indómito y singular que al insistir en el cuerpo de escrituras, los sustrae a la cómoda referencia a categorías fijas o estancas. En este sentido, lo ensayístico resulta solidario de una cierta improvisación que busca afrontar los desafíos de la singular realidad emergente con vistas a la consolidación del nuevo Estado y a la configuración de la nación. Pero, para concretar este fin, la nueva sociología debe conformar su lectura sobre la base de la interacción de tres figuras en las que se cohesiona el cuerpo social. En primer lugar, la historia. La clave para comprender la disposición de la futura nación debe ser extraída de una interpelación a lo muerto, a la morbidez patógena que subsiste a la celebridad de los nombres. En segundo lugar, el terror. Éste habita las interrupciones del tiempo histórico. Es respecto de él, la mueca suspendida y brutal en la que se actualiza la violencia y la locura. Finalmente, en tercer lugar, la simulación. Que en el reverso del terror, se consagra al equívoco que instituye la coexistencia anacrónica de lo tardío y lo iniciático. Continuo transformismo en el que se disuelven los contornos estables de las formas.
\end{abstract}

Palabras claves: Historia, Terror, Simulación, Locura, Positivismo

\begin{abstract}
The so-called "Argentine positivism" has, in its two biggest representatives, a noticeable essayistic form. In Ramos Mejía, as well as in Ingenieros, though particularly in the former, there is something indomitable and unique that lingers and, by being always present in the body of writing, it distances them from the simple use of fixed or stagnant categories. In this sense, the essayistic writing goes hand in hand with a certain improvisation that seeks to confront the challenges that result from the emerging reality in view of the consolidation of the new State and the configuration of the nation. But, in order to achieve this aim, the new sociology has to define its analysis taking into account the interaction of three figures in which the social body consolidates. In the first place, history. The key to understand the arrangement of the future nation must be taken from the questioning to the dead, to the pathogenic morbidity that survives famous names. Secondly, terror. It inhabits the interruptions of temporality. In connection to this, the brutal and suspended grimace in which violence and dementia are always present. Finally, simulation. In the other side of terror, it devotes to the confusion which establishes the anachronic coexistence between that which remains and that which is to come. A continuous transformation in which the stable outlines of shapes dissolve.
\end{abstract}

Keywords: History, Terror, Simulation, Madness, Positivism 


\section{Introducción}

La osificación de las etiquetas teóricas siempre culmina por doblegar los esmeros de justicia con los que la buena voluntad ha pretendido fundarlas. Las calcificaciones estancas no pueden, sino que terminar deshonrando irremisiblemente la confianza que se les rinde, a partir de una paradójica tensión que le es tan específica como inherente. La inflación formalizante es solidaria de una deflación elocuente en el plano del contenido, de manera que, una categoría acaba generalizándose en el mismo instante en que ya lo ha perdido todo. Pues, si parece ajustarse sin reserva alguna a todo caso, es porque ya no nombra efectivamente nada. Al menos, nada que posea aún consecuencias para el presente. Este riesgo de entumecimiento recae incluso sobre el llamado "positivismo argentino". En primer lugar, porque no debe desestimarse la heterogeneidad que habita una distancia infranqueable entre el positivismo europeo y la aplicación de dicha matriz teórica en contextos heteróclitos respecto de su lugar de origen. El positivismo de los márgenes posee un marcado perfil poiético ausente en la centralidad del primero, pues si la cavilación de este último se concentra en suturar las heridas del orden, el primero debe afrontar las realidades emergentes de su medio que pulsan con urgencia a la consolidación del naciente Estado y a la formación de la nación. La creación precede a toda ligadura reparatoria. En segundo lugar, porque si bien son visibles ciertas regularidades y anhelos comunes entre los autores reunidos canónicamente bajo tal categoría, dicha monocromía no debe censurar la espesura polimorfa que palpita en las escansiones particulares de cada escritura singular. Esto es particularmente visible en José María Ramos Mejía.

Es incluso más patente en la enrevesada confrontación dialéctica, que declina por momentos en irreprimible espanto, con la otra figura mayor del período, a la vez discípulo y parricida, José Ingenieros. Pues el pavor es a veces un dique con el que intentamos dejar a raya lo inquietante, es decir, aquello que rechazamos justamente porque se nos asemeja en una secreta intimidad. Terán aprehende algo de esta tensión al momento de poner la marca sobre el carácter ensayístico del así llamado "positivismo argentino". Pero no extrae las consecuencias últimas de aquello que nombra. No hay nada en común entre dos grandes ensayistas más que aquello mismo que los distancia. En otros términos, lo que de algún modo comparten radica en sus idiosincrasias heterogéneas, lo que los reúne son sus diferencias infranqueables. Esa nostalgia singular que, como diría Lukács, es en cada cuál dadora de la forma. En esta insalvable cercanía 
crepita el burilado constante de las formas que es la singularidad más distintiva y atractiva del ensayo. ${ }^{1}$ Parte de nuestro interés es demostrar y desmontar en la literatura de Ramos Mejía la trama fibrilar en la que hunde sus tentáculos para extraer, del abigarrado sedimento de la historia, su sustancia vital entretejida en el entrecruzamiento de complejas narraciones, donde reverbera la tradición ensayística nacional junto al sofisticado vanguardismo de las formas más refinadas de la literatura europea finisecular. Existe algo indómito, una fascinación salvaje por el abismo que expone a la tesitura sociodarwinista y psiquiátrico positivista de su escritura ante una implosión de las formas que a la vez que no puede sino que suscitar el desconcierto entre sus coetáneos, tiñe su voz de un embrujo sugestivo e hipnótico para el lector contemporáneo. En este sentido, la escritura de Ramos Mejía hace estallar todo corsé

\footnotetext{
${ }^{1}$ En una carta a su amigo Leo Popper sobre el ensayo, el joven Lukács lo concibe como algo mixto, ya que aún permanece en él una indiferencia entre arte y ciencia. Es singular y fragmentario, "cosa provisional y ocasional, sus resultados no se pueden ya justificar a sí mismos ante la posibilidad de un sistema" El ensayo es "nostalgia de valor y forma, de medida, orden y fin, no tiene simplemente un final que se pueda alcanzar aboliendo la nostalgia misma y haciendo de ella una tautología orgullosa" La nostalgia es en él dadora de forma. "El ensayo aporta esa configuración, esa dación de forma. Piensa en el ejemplo de los Parerga. El que estén antes o después del sistema no es una diferencia meramente cronológica: esa diferencia histórico-cronológica es sólo un símbolo de la separación de sus especies. Los Parerga antes del sistema crean de lo suyo propio sus presupuestos, crean el mundo entero partiendo de la nostalgia del sistema, para configurar -aparentemente- un ejemplo, una alusión; contienen inmanente e indeciblemente el sistema y su intrincación con la vida viva. Estarán, pues, siempre antes del sistema; aunque el sistema estuviera ya realizado, ninguno de sus ensayos sería una aplicación, sino siempre una creación nueva, un hacerse vivo en la vivencia real. Esta «aplicación» crea a la vez lo que juzga y lo juzgado, abarca y rodea un mundo entero para levantar a lo eterno algo que existió una vez y precisamente en Su unicidad. El ensayo es un juicio, pero lo esencial en él, lo que decide de su valor, no es la sentencia (como en el sistema), sino el proceso mismo de juzgar." Lukács, Gyorgy: Sobre la esencia y la forma del ensayo, en Qué es el ensayo, Bs. As., ed. El cuenco de plata, 2016, pp. 34 - 35) En tanto que Adorno acentúa esa intrincada tensión de amor y odio que lo habita de forma sustancial. "Pero el ensayo no permite que se le prescriba su jurisdicción. En lugar de producir algo científicamente o de crear algo artísticamente, su esfuerzo aún refleja el ocio de lo infantil, que sin ningún escrúpulo se inflama con lo que ya han hecho otros. Refleja lo amado y lo odiado en lugar de presentar el espíritu, según el modelo de una limitada moral de trabajo, como creación a partir de la nada. La dicha y el juego le son esenciales."
} Adorno, Theodor W.: El ensayo como forma, en Notas sobre literatura, Obra completa, 11, Madrid, ed. Akal, 2013, p. 12. 
nominal, a la vez fingido y tranquilizador que pervive bajo el falso conformismo del término positivismo.

Desde la intemperie que se sustrae a todo fetichismo categorial, intentaremos permanecer lo más cerca posible de nuestro objeto para ver surgir de él, de su propia configuración carnal, el lívido perfil de su forma singular. Buscaremos demostrar que ella cristaliza en el marco de tres tendencias que recorren su figura como la sangre lo hace respecto del cuerpo. En primer lugar, la historia. Del mismo modo que lo más selecto de la ensayística de generaciones anteriores, Ramos Mejía (esto vale también para Ingenieros), inscribe el problema de la configuración del Estado y de la creación de la nación bajo el espectro de una interrogación permanente con lo muerto que, sin embargo, mantiene un privilegiado vínculo esotérico con lo vivo. La clave para comprender la disposición de la futura nación debe extirparse de un fárrago de sombras, de la polifonía difusa de voces sin cuerpos que hunden su gravitación brumosa en el exótico vapor de los tiempos de la colonia y de las guerras de emancipación. Pero si bien comparte con la narrativa romántica la idea de la lucha como motor de la historia, tanto una como la otra dejan de percibirse en el acmé glorioso del héroe, por el contrario, desintegran su materialidad en la temporalidad radical que se vierte, primero, sobre el recipiente invisible de la anatómica laberíntica de la arquitectura cerebral, y luego, en el microscópico submundo calcáreo que oculta el protoplasma seminal que determina paradójicamente las macroscópicas conflagraciones de la multitud. Estamos ante el registro de los "móviles ocultos". Es decir, un mecanismo que confecciona una hermenéutica en la que la florescencia de los fenómenos masivos y patológicos, efectivamente visibles en la historia, adquieren significado al ser reenviados a la efervescencia de lo infinitesimal, por consiguiente al ámbito de su causación oscura, allí donde se imponen los designios invisibles.

En segundo lugar, el terror. La continuidad del tiempo histórico se ve dominada por los intersticios en los que irrumpe el trastorno. La fuerza de una vitalidad monstruosa y desmadrada que se desahoga en interrupciones desnudas, al calor del hierro ardiente, donde azota la violencia. La sola incidencia de estos momentos decisivos haría caer fácilmente la vacuidad intrínseca y la solvencia relativa del calificativo positivista para designar a nuestro autor. En Ramos Mejía la espuma cientificista en la que se atavía el eminente psicopatólogo se desvanece ante el hechizo de la locura o ante el semblante extraviado de la multitud que fulmina la mirada con su 
rostro meduseo. Locura y multitud, figuras del pharmakon, ese oxímoron viviente, que condensa en sí mismo un exceso paradójico, a la vez detritus maldito y poíesis genial, se revelan como el auténtico, aunque anómalo, sujeto de la historia.

Finalmente, en tercer lugar, la metamorfosis y la simulación. En su registro continuo la temporalidad histórica encierra, como un milhojas de tiempos simultáneos, las supervivencias atávicas de arcaísmos vergonzantes, al mismo tiempo que en la fosforescencia larvaria de la materia, el investigador perspicaz capta los estados iniciáticos de un proceso sano o enfermo que se mantiene, sin embargo, en devenir permanente. La metamorfosis es el apogeo de la labilidad de las formas. Tiempo facetado en el que el impulso sucesivo borra los contornos a la vez que conserva las marcas de la totalidad virtual de sus transformaciones. Bajo la égida de esta dinámica, la extrañeza se devela como la realidad del instante suspendido. El equívoco gobierna el desconcierto producto de la desintegración de los contornos estables de la materia. Lucha por la vida y selección natural traducen, en términos de liturgia darwinista, la ebullición de lo vivo cuando habita el desgarramiento. Torbellino supurante y purulento, se supera a sí mismo en las nuevas condiciones que sabe crear desde el magma de cohabitación febril de superposición, disfraz y farsa. De ahí la obsesión rumiante que busca incansablemente descifrar los signos. El insomnio compulsivo que denuncia en la superficie de todo rostro la piel plástica o engomada de la máscara. Embebido en el azufre de las mutaciones, el mundo deviene escenario infinito, teatro del drama o vodevil risueño y carnavalesco, todo se hunde en el vértigo satánico del artificio, donde la crueldad de la lucha por la vida se anuda, ante el observador perplejo, con el pliegue y repliegue de la simulación y el disimulo.

\section{I - La Historia:}

\section{1. Neurosis y Locura en la Historia.}

Con seguridad, antes nadie, y tal vez luego, solo algunos pocos, se han atrevido a ensayar en la literatura nacional una consustancialidad tan extravagante y desviada entre la neurosis o la locura y la historia. Fuera de nuestras letras nativas quizás la cosa cambie, aunque ciertamente ello se muestre al margen de esa reviviscencia bizarra y esa mixtura aberrante de cientificismo y verbosidad extraviada que configura la cadencia singular de los escritos de Ramos Mejía. Es cierto que siempre es posible abuzar de la 
analogía y reenviar tal o cual elemento a narrativas pasadas y foráneas. Seguramente sobre esa constelación histórica que anuda la psiquiatría y la criminología bajo el encuadre positivista, o la anatómica mórbida en el ceñidor de la frenología o de la fantasmática lombrosiana. Pero ningún reenvío de esta clase puede trazar más que la genealogía de algunos rasgos o elementos comunes, por el contrario, jamás podrá dar cuenta de esa marca idiosincrática que es el producto de un impulso maníaco y excesivo que lleva a nuestro autor a proponerse la desmesurada tarea de escribir una historia nacional bajo el influjo enfermizo de la neurosis y de la locura.

En una conferencia pronunciada en París y dedicada a Ramos Mejía, Horacio González puntúa la cercanía de la idea de una coalescencia oculta entre historia y locura con la conocida sentencia de Macbeth en la que Shakespeare insinúa esta misma superposición por la que el devenir histórico se manifiesta como el relato de un loco y por tal motivo, carente en absoluto de sentido. Esta primera cercanía a la literatura, como luego se verá, está lejos de mostrarse circunstancial. Por lo demás, este posicionamiento "eminentemente literario", nos habla de una conciencia desgarrada que intenta afirmarse en el silencio de espacios infinitos. Estado de soledad radical, deviene vulnerabilidad esencial, fría indigencia ante un mundo que sobreviene esquivo y monstruoso. "Sería el lamento del hombre ambicioso fracasado o la autoindulgencia del asesino que al no conseguir sus propósitos imagina que el mundo está tan desarreglado como su propia conciencia ruinosa." ${ }^{2}$ Lúcida luminiscencia, cristaliza en una sensibilidad melancólica, como la añeja sentencia del Eclesiastés, enuncia la vanidad de todo ímpetu humano. Nada de lo humano escapa a la putrefacción. Todas nuestras voces serán acalladas y el resplandor en las pupilas, finalmente olvidado.

Lucidez de la declinación, se articula como una "doble ironía". "Primero, sobre el esfuerzo humano, cuyas consecuencias escaparían a la comprensión de los hombres. Y luego sobre el propio relato, cuyo sentido último no estaría a disposición de los cronistas." ${ }^{3}$ La sustracción del significado, como señala Horacio González, culminaría recayendo tanto sobre las palabras como sobre los actos. Es este punto de anonadación y terror el que, sin embargo, da inicio a la especulación de Ramos Mejía. De ahí que bajo la pátina biologicista y formalista, su escritura se sustraiga (tal vez a su pesar como

\footnotetext{
${ }^{2}$ González, Horacio: El prologuista francés y la locura de los símbolos: el "incidente" Ramos Mejía, en Retórica y locura, Bs. As., ed. Colihue, 2004, p. 17.

${ }^{3}$ Idem.
} 
efecto de un impulso que secretamente lo habita) constantemente a todo pretendido sometimiento a los parámetros ordinarios de un racionalismo homogéneo de tinte positivo. Jamás se esfuma del todo cierto perfil trágico indiscernible de un rancio tufillo teológico y oscurantista como fondo actuante en su producción intelectual. Fondo particularmente significativo para su concepción de la historia y que por ello demanda, para su comprensión, remitir su filiación a otro orden de tradición.

La conjunción sagrada de neurosis o locura y la temporalidad histórica posee la forma del escándalo, el paroxismo de un esquema que inicia justamente por su carácter excesivo e inabarcable. En ella la secularización se anuda indisolublemente a la blasfemia como delirada inversión de Dios bajo su sombra aberrante. Pues sólo en el hiato abierto por esta inversión el hombre accede a la conciencia alucinada de su destino de auto-creación. La locura es entonces el auténtico rostro del hombre en un mundo en el que Dios falta. Es decir, "la ausencia de Dios" es el reverso necesario de "la presencia de la locura en la historia", y esta presencia es la señal irrebatible de la inherencia existente entre el hombre y la locura. Pero si la locura individual o bien su polifonía masiva es inmanente al acontecer histórico, ¿cómo es posible entonces el pensamiento? ¿Cómo puede diferenciarse el análisis crítico de una aciaga pesadilla? La autolegitimación del intelectual se sustenta en la distancia helada de la ironía. El investigador, en tanto que integrante de una elite que se auto-percibe como sinécdoque de la Nación, aporta su clarividencia por el efecto de una lejanía que lo reserva del sopor reflexivo que caracteriza al hombre de multitud. Del mismo modo, la consciencia irónica, aquella que inscribe la doble sustracción, lo mantiene en ese anclaje de vigilia desde donde se percibe como absurda dislocación, refinada o bestial, las palabras y los actos del aglutinado marasmo del animal sonámbulo.

En forma análoga a como el punto de partida para toda mirada irónica radica en el sujeto irónico, la consustancialidad de locura e historia es indivisible de la mirada del sujeto que la afirma y que la encuentra clareando en cada estado valetudinario o como correlato de la vesania ridícula desarticulando al lenguaje. A partir de dicha aquiescencia la patología nacional puede decantarse como un proceso en permanente develamiento articulado en el trascurso del acontecer histórico. Develamiento que emerge del espanto y deviene alternante, entre la solemnidad trágica y una bufa rebeldía. El irónico es el prodigioso observador del desorden universal al que, sin embargo, busca incesantemente codificar desde la distancia que su propia consciencia 
irónica le aporta. ${ }^{4}$ El devenir en la locura es como esa ironía de la naturaleza de la que habla Kierkegaard. Ella sólo es visible para aquel que interpela a la naturaleza como a una "persona", de modo que ella "le gasta bromas o le confía sus preocupaciones y sus penas". Por eso, aunque la ironía no se halle en la naturaleza, quien posee un temperamento desarrollado en ella, la encuentra en esos momentos en que "la naturaleza yuxtapone irónicamente los extremos más alejados.” En el encadenamiento alucinado que justifica las combinaciones más grotescas y pueriles. La fauna más elemental ocupando las instancias decisivas en la construcción de nuestra identidad nacional. La historia tejida en la ebullición rabiosa de los alienados ya sean éstos célebres o anónimos. La mirada irónica resulta entonces inseparable de lo humorístico, abrasivo sarcasmo que, según Kierkegaard, tiene su origen en "la consideración del pecado en el mundo". 5 Como un Jano rioplatense, Ramos Mejía encuentra en la locura el elemento tajante de su propia escisión que, por lo demás, queda indeleblemente exhibido en el movimiento inmanente de su escritura. Por un lado, en tanto que escritor afectado por la pestilencia marchita de la literatura decadentista que lo arroja a la fascinación fulminante por la conjunción de lo bello y lo enfermizo, y por el otro, como científico biologicista que busca instalarse en la protección esterilizada y neutral que le brinda el discurso médico, tanto más patológico, contradictoriamente, cuanto más a salvo se concibe respecto de su objeto.

Sin embargo, la cosa está ahí. Espera, desde la aurora de los tiempos, a quién le devuelva la palabra. Ante "ciertos hechos", escribe Ramos Mejía, es necesario "hacer intervenir a la psicología mórbida", principalmente en el caso de "aquellos individuos a quienes la Providencia ha colmado con sus dones". 6 Existe una causa bifronte, conforme a una yuxtaposición irónica de los extremos más distantes, que se muestra

\footnotetext{
${ }^{4}$ Este distanciamiento se configura con aciaga regularidad como sueño de la razón que se erige en clave universal y esotérica de todos los fenómenos. En este sentido, la veladura positivista de Ramos Mejía se desquicia en la convicción de aquel que cree poseer todos los significantes, en tanto que legalidad implícita a la manifestación aparente de las cosas. “(...) el positivismo confía en que la observación unida a la razón puede detectar un orden, una legalidad, que escapa a quienes están desposeídos de estos instrumentos intelectuales. Además, y esto es fundamental, quien encuentre esa clave podrá prever y hasta encauzar el curso de las grandes movilizaciones populares." Terán, Oscar: Historia de las ideas en la Argentina, diez lecciones iniciales, 1810 - 1980, Bs. As., ed. Siglo veintiuno, 2008, p. 130.

${ }^{5}$ Kierkegaard, Soren: Sobre el concepto de ironía, en Escritos volumen I, Madrid, ed. Trotta, 2000, p.282.

${ }^{6}$ Ramos Mejía, José María: Las neurosis de los hombres célebres en la historia argentina, Bs. As., ed. Biblioteca nacional, 2013, p. 154.
} 
subrepticiamente en la singularidad excepcional de ciertos hombres de nuestra historia. Los dones de la Providencia tienen la forma de un oxímoron que condensa fuerzas inconmensurables, de manera que enhebra en un mismo cause la heterogeneidad más extrema y la otredad más radical. Pues, "todo esto nos induce a creer que efectivamente el genio y la locura tienen algunos puntos de afinidad". ${ }^{7}$ La tesis de que los estados extremos remiten a una oculta inherencia de locura y genialidad tiene una vastísima tradición, incluso infinitamente más compleja y vetusta que la datación simplista a la que la somete Ramos Mejía al vincularla al auge de la psiquiatría del siglo XIX. "El que quiera cerciorarse de la mayor o menor exactitud que encierra esta proposición, todavía muy discutible, puede leer a Wagner, a Dragon, a Bigot, a Lucas, a Moreau de Tours, para convencerse de que esos dos productos tan opuestos dimanan, tal vez, de un tronco común y tienen algunas de sus fases idénticas." 8 Invirtiendo la sucesión temporal, la confluencia de genio y locura se encuentra presente, aunque configurada de diversos modos, en la literatura decadentista contemporánea a Ramos Mejía, en el romanticismo, en el renacimiento, particularmente en Marsilio Ficino y Robert Burton, finalmente en la tradición aristotélica en el esencial problema XXX, 1, del cual todos los demás son deudores, por sólo nombrar los puntos más intensos y mayores en la historia de esta idea. En este sentido, la locura -como lo será a posteriori la multitud- describe un punto de extrema intensidad en la historia, un escándalo ante lo inescindible que deja entreverse como una figura del pharmakon, simultáneamente veneno y remedio, obscena brutalidad y creación genial.

\section{2. De la barbarie a la locura. El mal en la Nación.}

En el marco de su primer libro, Las neurosis de los hombres célebres en la historia argentina la idea del genio cumple la función de doble coagulante. Por un lado, ella representa el modo en que la locura juega un rol decisivo en la historia, encarnada en el individuo excepcional. Por el otro, este carácter decisivo confluye con la idiosincrasia singular de nuestra semblanza nacional, ya que el genio es el prototipo del meneur, es decir, el líder o caudillo alrededor del cual las multitudes alcanzan un cierto equilibrio inestable, por lo menos, circunstancial. Este doble encaje posee notorias

\footnotetext{
${ }^{7}$ Ibid., pp. 154 - 155.

${ }^{8}$ Ibid., pp. 155.
} 
reminiscencias sarmientinas como efecto de la interpelación que Ramos Mejía hace de la tradición ensayística precedente. Ahora bien, estas reminiscencias no deben llevar a autoengaños continuistas, por el contrario, es preciso interpretarlas en el contexto de sus desplazamientos y reconfiguraciones en el que la invención de las formas cristaliza en un movimiento suspendido donde el declive de lo antiguo viene a fecundar la emergencia de lo nuevo.

En Sarmiento el genio ingrávido de un pueblo también viene a personificarse en una figura excepcional. Facundo es la encarnación del pueblo porque es inescindible de la barbarie. Ella representa el anatema inscripto en la condición execrable que caracteriza a la campaña y al desierto argentino. Como alteridad conflictiva respecto de la ciudad, escena de la civilización por antonomasia, describe la cuña maldita con la que se entreteje el drama de la identidad nacional. En este sentido, la nacionalidad aparece como el fruto maligno que surge del desgarro de las fuerzas en conflicto. Esta herida contamina, sin embargo, todos los ámbitos de la existencia. Pues la barbarie en Sarmiento se muestra como un polimorfismo que alcanza a todos los estratos, diseminando su sulfúrica toxicidad a través de las nervaduras venosas del cuerpo social. En primer lugar, ella se manifiesta como condensación de la degradación vinculada al "medio natural". Pero este primer registro transfiere rápidamente su veneno hacia la formación política. El despotismo es la forma emergente de la barbarie como organización del poder. Finalmente, la barbarie designa la condición subjetiva del tipo de individuo procedente de este entorno cultural. En este sentido, ella deviene "discurso psicológico" anclado sobre la rusticidad de los instintos y la violencia de las pasiones.

En cuanto discurso acerca del carácter y las pasiones, la barbarie representa el trasfondo simbólico sobre el que se recorta la dimensión de la locura. Según Hugo Vezzetti este deslizamiento denuncia un evidente "empobrecimiento". 9 Pero este “empobrecimiento" puede darse por la dimensión misma de la figura de Sarmiento, no así por la reconfiguración de los problemas que suscitan, por lo pronto, enorme complejidad. Como heredero de Sarmiento, Ramos Mejía inscribe su especulación bajo la égida de una casuística que se propone vencer, como aquel, los enigmas de la nacionalidad argentina. Pues “(...) si en el texto de Sarmiento la biografía es a la vez

\footnotetext{
9 "De cualquier modo, es preciso reconocer que de Sarmiento a Ramos Mejía el recurso interpretativo y narrativo sufre un evidente empobrecimiento." Vezzetti, Hugo: La locura en la Argentina, Bs. As., ed. Paidós, 1985, pp. 91 - 92.
} 
directamente historia social, esa personificación de los conflictos (por ejemplo, Rosas Rivadavia, Quiroga - Paz) anticipa un «estudio de caso» en el que cierta psicología busca revelar los enigmas de la nación. En esa dirección inscribirá J. M. Ramos Mejía su peculiar abordaje de la locura y la historia." ${ }^{10}$ El romanticismo aporta a Sarmiento la idea de una consustancialidad entre el destino personal y el de la Nación bajo la conformación del genio en un doble movimiento simultáneo en el que Facundo aparece, simultáneamente, como anamorfosis y gemelo monstruoso del escritor. "En el mismo movimiento en que el personaje histórico adviene a la función de arquetipo, indagarlo aportará cierta clave del destino nacional y por lo mismo ese Facundo fabuloso constituye recíprocamente a Sarmiento como un héroe: es Edipo que vuelve a derrotar a la Esfinge." 11 En esta imposición a la que el ego somete al misterio se culmina edificando la permanencia de un ideal. El de los hombres de la patria, legisladores míticos, educadores iniciáticos, pero ante todo fundadores de valor, metáforas y metonimias del ser nacional.

La psicología de la barbarie centra su mirada en la desmesura, es decir, en el abyecto abismo del desborde pasional que se precipita, indolente, como violencia naturalizada y por eso mismo, sustraído y distante respecto a cualquier orden que se pretenda supeditado al dominio de la razón. La pasión describe la multiplicidad de las fuerzas enajenantes que pulsan irremisiblemente hacia la conflagración. En ese sentido, nombran aún en un lenguaje romantizado y novelesco, aquello que en la metaforología cientificista de Ramos Mejía se vuelca como intensidad de excitación del aparato enervador del sistema nervioso general. El desplazamiento no es menor y debe evaluarse interrupciones y continuidades de los diversos usos metafóricos. Sarmiento inaugura, aunque en una existencia aún larvaria, el discurso "psicopatológico" de la sociedad argentina, aunque con marcado optimismo en el Facundo respecto del determinismo racial de Conflicto y armonía de las razas en américa. "Ante todo, el medio físico y geográfico y su expresión en el plano del carácter: la resignación, el despotismo, la ociosidad; en esa descripción, las referencias a caracteres raciales ceden rápidamente su importancia a la preponderancia del medio físico y moral; algo que resalta más aun en el capítulo de las propuestas o soluciones: el orden y la moralización

\footnotetext{
${ }^{10}$ Ibid., p. 91.

${ }^{11}$ Ibid., p. 92.
} 
correlativos a la inmigración, el trabajo y la educación podrán cambiar esa sociedad en diez años."12 El enunciado de Vezzetti se muestra coherente y a grandes rasgos, incluso nosotros lo compartimos. Pues tomando como referencia este optimismo del Sarmiento del Facundo, Vezzetti lee el declive, ese empobrecimiento que se derrama resquebrajado y putrefacto, como teoría de la degeneración. ${ }^{13} \mathrm{Si}$ bien esto último es cierto, cabe evaluarse la complejidad que adquiere el significante locura (y sus afines) en la escritura de Ramos Mejía.

\section{3. La locura en Ramos Mejía.}

"Es la hipocresía como método, un ardid de la razón teatral en su presunción de inventar la verdad." 14

El principal cuestionamiento a la lectura de Vezzetti radica en la seriedad con la que interpreta los enunciados de Ramos Mejía. Una vez que se ha evaluado la importancia de la doctrina positivista para el horizonte histórico de mediados del siglo XIX, y una vez armados de un arsenal crítico respecto de sus dogmatismos y consecuencias nefastas, resulta más o menos simple una toma de posición que con el tiempo culmina por anquilosarse, sofocando con ella y en última instancia, todo resto de asombro. En esto radica nuestra reticencia a la excesiva manipulación de una categoría tan plástica como la de positivismo. En modo alguno porque no creamos que su influencia pueda percibirse en Ramos Mejía, sino porque de ninguna manera su escritura se deja clausurar sin restos por aquella denominación. No nos resulta algo tan claro ni unívoco, qué pueda representar la adiposa descomposición de lo social para Ramos Mejía, ni menos aún, la constelación significativa y paradójica de aquello que entiende como locura. Tratemos, contrariamente, de desandar estas referencias desde su mismo marasmo interno.

\footnotetext{
${ }^{12}$ Ibid., p. 94.

13 "En ese sentido, del Facundo a los "hombres célebres" y a Las multitudes argentinas, esa embrionaria detección histórica de una zona perturbada de la nacionalidad se degrada en una versión que únicamente verá el componente biológico y psicopatológico, sostenido por la teoría de la degeneración." Idem.

${ }^{14}$ Didi-Huberman, George: La invención de la histeria, Charcot y la iconografía de la Salpêtrière, Madrid, ed. Cátedra, 2007, p. 18.
} 
El vínculo de genialidad y locura recae, para la perspectiva romántica, en la fuerza inconmensurable de los impulsos. En ese sentido, la biografía resulta el género literario predilecto, en la medida en que da cuenta, por intermedio de la superposición de relato y vida, de la rapsódica articulación de ese intangible, aunque fundamental, mundo íntimo de los personajes excepcionales. El genio es, de este modo, el eco encarnado de las intensidades pasionales que recorren la totalidad del cuerpo social. Pero a diferencia de esta mirada que se posa ineluctable y exclusivamente sobre el héroe, la personalidad genial es ahora configurada bajo el prisma de la herencia patológica. "Semejantes dislocamientos, profundos, incurables, aparecen en algunos con todo su horrible aspecto y vienen como amarrados a la cuna, absorbidos en la leche materna; parece que al nacer trajeran un pedazo del alma del padre o la madre, como fundidos en su cabeza con todas sus sombras y su colorido enfermizo; es que no han podido eludir el peso abrumador de este misterio inescrutable que llamamos herencia patológica." 15

La temporalidad histórica se amalgama con la evolución del protoplasma vital en el contexto de la transcripción social -por lo demás, abusiva y por momentos disparatada- de la doctrina darwinista de lucha por la vida, herencia, adaptación y selección natural. En el tiempo actual reverbera la supervivencia de una temporalidad difusa que se niega a perecer. La herencia pervive como un suplemento atávico de lo muerto en lo vivo que retorna, parpadeante, para reclamar en el presente su pretérita soberanía. La temporalidad de la herencia es la de una memoria en la que insiste la inquietud desarticulante del anacronismo. Una confusión de actualidad y arcaísmo se entretejen en un tiempo híbrido que encuentra su solidificación parcial en un plexo epidérmico y carnal en el que cohabitan el fósil junto a una germinalidad primitiva o incipiente. En la virtualidad de toda morbosidad presente persiste el incesante marchitamiento de un tiempo en continuo declinar, junto a la deformidad embrionaria de lo aún no realizado. "El tiempo ocurre en la memoria, que pasa por centros imantados por herencias que combinan petrificaciones en grado diverso de las prácticas sociales. Restos fósiles de la experiencia y adhesiones del comportamiento a una hipótesis de actualización sin búsqueda de raíces, que hacen a la espesura que se conjuga en un punto dado de la sociedad un mapa mental extraído de distintos procesos

\footnotetext{
${ }^{15}$ Ramos Mejía, José María: Las neurosis de los hombres célebres en la historia argentina, p. 155.
} 
colectivos de evocación." ${ }^{16}$ Pero más allá de esta arborescencia de duraciones heterogéneas, la biología moderna se perfila como el hilo de oro capaz de doblegar el vértigo inmanente de este laberinto. Como una repetición satírica y diferencial del texto sarmientino, Ramos Mejía -en cuanto poseedor del conocimiento de lo biológico-, se presenta como el nuevo conjurador de enigmas. La biología finalmente ha robado a la vieja esfinge su "silencio desesperante". ${ }^{17} \mathrm{La}$ violación del secreto se cataliza en progreso. "Nada puede resistirse al espíritu de progreso que nos empuja." 18 En Ramos Mejía conviven, sin solución de continuidad, la idea de una temporalidad dramáticamente indomeñable junto a la fe pueril en una concepción lineal del progreso que se destila de las nervaduras capilares de su tiempo histórico. Por eso no duda en afirmar que la biología ha realizado la profecía de Voltaire, ha devenido la llave maestra que abre el inframundo de la "pulpa divina que palpita bajo la cúpula del cráneo". Resulta así, el código que desoculta las causas latentes remitiendo, término a término, la escena de lo visible a su causación invisible. En tanto que fetichizada, esta disciplina se concibe como un tiempo y una economía sin pérdidas ni restos, pues en ella todo gasto en lo manifiesto esconde la esperanza de ser saldado remitiéndolo a su registro invisible, transitoriamente oculto o esotérico. ${ }^{19}$

Ahora bien, el hundimiento del tiempo histórico en el biológico bajo la ignominia de la patología tiene consecuencias irreversibles para la historiografía. El mismo Ramos Mejía es consciente de la doble luminiscencia de su idea, simultáneamente genial y abyecta, tan fundamental que parece diluirse en el absurdo. Nuevamente tocamos ese punto de anonadamiento en el que se desvanecen las distinciones y las formas se ahogan en el espesor brumoso que fusiona lucidez y locura. "Suponer estados excepcionales, perturbaciones del cerebro, leves o profundas, en individuos que han mostrado en todos los actos de su existencia precisamente lo contrario; que muchos de ellos han descollado por su cordura y por el brillo de sus

\footnotetext{
${ }^{16}$ González, Horacio: José María Ramos Mejía: terror, locura y misticismo, estudio preliminar a Las neurosis de los hombres célebres en la historia argentina, p. 14.

${ }^{17}$ Ramos Mejía, José María: Las neurosis de los hombres célebres en la historia argentina, p. 122.

${ }^{18}$ Ibid., p. 129.

${ }^{19}$ Usamos el término fetiche en el doble registro. Por un lado, en cuanto objeto que esconde tras su faz fascinante el modo de producción que lo ha llevado a cabo, por el otro, en cuanto objeto a partir del cual alguien encubre u oculta su falta.
} 
facultades y no por sus extravagancias (de las cuales nuestra historia no se ha dignado ocuparse) es cometer una locura o tratar de probar un absurdo." ${ }^{20}$ Por el contrario, la historiografía tradicional ha caído en la mitificación, justamente, por su reluctancia inclaudicable a medirse con lo absurdo. Por ello se ha clausurado en la parcialidad, mutilando al héroe que, sin embargo, pretendía glorificar. "La aplicación de estos principios a nuestra historia parecerá impropia porque hemos conocido la vida de casi todos nuestros hombres célebres transmitida por la tradición fabulosa y desfigurada, o por la biografía meliflua de sus biógrafos amigos, y porque muchos historiadores «han creado» el personaje a su capricho y nos lo han impuesto difundiendo errores que hoy es difícil combatir."21

La historiografía tradicional es denunciada como edulcorada fabulación. En ella, el anecdotario se ciñe al placer subalterno de ataviar la imagen del héroe bajo el dominio de una idea predeterminada que supura un dulzor solemne que raya, por eso mismo, con la caricatura. El historiador no debe abandonarse a la indulgente fantasmagoría que construye ídolos con pies de barro en el cuerpo de una literatura de dudosa calidad. Tampoco puede huir ante la encrucijada que exige, para su develamiento, una evaluación más compleja e integral que transgreda el límite dado por el mero semblante proverbial del personaje abordado. Por el contrario, la historiografía que propone Ramos Mejía fluye hacia ese punto de convergencia en el que se coagula, en una nueva forma, lo público y lo privado, la gran proeza militar junto al cosmos microscópico de la vida neuronal. Pues, de lo que se trata, es de hablar de "la misma historia argentina" pero abordada ahora desde la incidencia de lo patológico en el interior de la batalla o acontecer histórico. Ver al prócer bajo el cristal de la neurosis, es decir, "del terror, la locura y el psiquismo impostor." 22 De ahí la obsesiva adoración que realiza de esas "nimiedades", minucias o migajas que acumula con la lascivia del coleccionista y que el historiador ordinario pasa por alto. "Por esto, para conocerles es menester no detenerse en la puerta del hogar, menospreciando ciertas nimiedades de carácter puramente privado, ciertas debilidades más o menos groseras, como indignas de la pompa y majestad de la historia, porque sería cometer un absurdo y falsear la

\footnotetext{
${ }^{20}$ Ramos Mejía, José María: Las neurosis de los hombres célebres en la historia argentina, p. 155.

${ }^{21}$ Ibid., p. 156.

${ }^{22}$ González, Horacio: José María Ramos Mejía: terror, locura y misticismo, p. 12.
} 
verdad, despreciar un criterio de inapreciable valor para la evaluación de los hechos.”23 De este modo, por mediación de lo biológico, el magma patógeno de lo vivo irrumpe en la escena pública e invade, con su furia corpuscular, el anquilosado decurso de la cronología histórica.

La mirada analítica disecciona, como un escarpelo, la opacidad de los cuerpos. Abre sus impudicias ocultas y las exhibe con cruel indiferencia bajo una pretendida luz aséptica. Abusa, ebria en su pulsión de dominio, de cada límite que pretenda replegarse en la íntima protección de alguna zona eclipsada. La "anatomía de la vida íntima" revela en toda su "desnudez", las "sombras" y los "secretos" crípticos, a los que otorga, por otra parte, relieve histórico. Sin embargo, el modo de exorcizar esta dimensión demoníaca de la locura en la historia, cataliza en Ramos Mejía bajo la forma de un esquema edificado sobre la base de un lenguaje exuberante y bizarro que denuncia en acto un desfase entre su infinita potencia constituyente y un olvido pueril e inmotivado de su decisiva eficacia metafórica. En el hiato abierto por este desfase se percibe la íntima escisión sobre la que se sustenta el psiquismo impostor. Simultáneamente objeto y sujeto del discurso psiquiátrico, tanto más eficaz, en cuanto menos percibido, actuante desde el crepúsculo de la consciencia, siempre más acá o más allá de su despierta legalidad.

Por eso, no sorprende que en el contexto de esta tesitura, la metáfora de la "histología de la historia" que Ramos Mejía agita para nominar su metodología de trabajo, funcione bajo el primado de esta idealización de lo biológico que se exhibe como mirada fascinada. "Ella sirve para el estudio de los móviles ocultos que encierran ciertas acciones, al parecer incomprensibles, descubre el misterioso motor de muchas determinaciones caprichosas, la índole de sus tendencias, la naturaleza íntima de su carácter, escudriñando la vida hasta en sus más pueriles manifestaciones; de la misma manera que la histología propiamente dicha, con su espíritu esencialmente analítico, estudia y describe el último de los elementos anatómicos, dándose cuenta por su evolución y transformaciones de todos los procesos orgánicos ulteriores." ${ }^{24} \mathrm{La}$ formulación es extremadamente seductora, por eso mismo sospechosa. En su megalomanía, tiende a una clausura en torno a un destello hipnótico que deviene susceptible de condensar una visión totalizante, diáfana irradiación de un cuerpo sin

\footnotetext{
${ }^{23}$ Ramos Mejía, José María: Las neurosis de los hombres célebres en la historia argentina, p. 157.

${ }^{24}$ Idem.
} 
sombras. "No escapa nada a este método agresivo de análisis, a esta luz penetrante y sutil que se insinúa por los más oscuros repliegues del alma humana, que interroga al cuerpo para explicarse la evolución del espíritu y que desciende hasta el hombre privado, buscando en sus idiosincrasias morales el complemento necesario del hombre público." ${ }^{25}$ En la fosforescencia de esta plenitud de vigilia, el sujeto finalmente se pierde en el mismo instante súbito en el que cree triunfar en la obtención de un saber sin fisuras que, irónicamente, se diluye en alienación no percibida.

Este saber al que nada escapa se asemeja, por lo pronto, a la autosugestión. Palabra clave de la época que designa ese estado psíquico que denuncia una manipulación sutil e impalpable en la que se anudan identificaciones latentes, aunque estas sean operadas por algo en el mismo agente que es incapaz de percibir la maquinación oculta que lo mueve a actuar así. El psiquismo impostor deja su marca sugestiva en la misma escritura de Ramos Mejía. Marca incandescente, se aviva desde la exterioridad imperceptible a la que la arroja una presunta ciencia sin falta. La hipocresía, el movimiento intrínseco del psiquismo impostor, habita la escena donde el conocimiento se exhibe sobre el fondo angustiante de un desconocimiento anterior, pues emerge de una fisura que permanece ocluida tras la grandilocuencia manifiesta de un presunto saber sin fallas. Por eso, en Ramos Mejía, la locura se "elabora" y "realiza" en la ampulosidad gongorista de su escritura, como reflejo deformante y doble siniestro de un saber hipertrofiado. "Pero verdaderamente es un escritor que toma como sujeto de la escritura al proceso de la locura. La locura puede enhebrar los actos de escritura que pueden convertirse en una misma cosa con la propia locura." ${ }^{26}$ Locura e historia alcanzan en él esa fruición sublime que entreteje incesantemente la inquietante indistinción entre "ciencia" y "saber salvaje".

De este modo, la locura es llamada a manifestarse en la historia bajo el registro del espectáculo y sobre el fondo de una doble coacción. Por un lado, la del omnipotente saber médico que supuestamente la describe ciñéndola al control de sus taxonomías, y por el otro, el de la mirada fascinada del artista que la invoca o evoca en su escritura, aunque como consecuencia del cono de penumbra en el que permanece su fisura íntima, desconoce el grado de solidaridad inventiva que lo une, indisolublemente, al destino de su objeto. En este doble movimiento, las figuras de la locura emergen de un interés

\footnotetext{
${ }^{25}$ Ibid., pp. $157-158$.

${ }^{26}$ González, Horacio: José María Ramos Mejía: terror, locura y misticismo, p. 9.
} 
compulsivo por el espectáculo. Por eso mismo, la "violencia del ver" constituida en ideal científico accede a su verdad en el límite de la frustración. Pues la pulsión escópica del discurso de lo biológico que busca la traducción visible de lo invisible, se muestra análoga a aquella curiosidad pueril del niño que Baudelaire describe comprometido y absorto en la pesquisa del alma de sus juguetes, como él choca finalmente contra esa perplejidad angustiada y desconcertante que le provoca la sustracción irremediable de la primera y la rotura irreversible de sus juguetes. ${ }^{27}$ Como señala George Didi-Huberman para el caso particular de la histeria, sobre la imagen confluyen idealmente el fantasma de la locura y el fantasma del saber. Teatralidad de los cuerpos y teatralidad de la escritura, hieratismo de la locura en la historia. La locura deviene, por lo tanto, inseparable del teatro, del artificio, de la simulación y la invención. Ramos Mejía ejemplifica aquello que Nietzsche denuncia y que DidiHuberman exhibe de modo excepcional, el hecho de que estemos incapacitados de "no asistir como inventores de cualquier fenómeno". ${ }^{28}$ Escribir la locura en la historia es un acto que se sumerge en la realidad esencial de la invención. Es el decisivo instante de un acto complejo en el que se perfilan, al menos, tres acepciones. "Imaginar; imaginar hasta el punto de «crear», como suele decirse. Además, fingir, es decir, exagerar en la imaginación, sobrecrear; en una palabra, es mentir por la facultad del ingenio, si no del genio. (...) Inventar es, finalmente, toparse y caer, en seco, al chocar con la cosa, con la «cosa misma»; es volver sobre ella, invenire, y desvelarla, quién sabe..." 29 Escribir la locura no puede ser otra cosa que invenire, es decir, producir un invento, un in-ventus, algo que en primer lugar viene de dentro.

\footnotetext{
27 "La mayoría de los críos quieren sobre todo ver el alma, unos al cabo de algún tiempo de ejercicio, otros enseguida. La invasión más o menos rápida de ese deseo es la que decide la mayor o menor longevidad del juguete. No tengo el valor de reprochar esa manía infantil: es una primera tendencia metafísica. Una vez que ese deseo se fija en la médula cerebral del niño, llena sus dedos y sus uñas de una agilidad y una fuerza singulares. El niño da vueltas y más vueltas a su juguete, lo araña, lo golpea contra las paredes, lo tira al suelo. De vez en cuando hace que recomience sus movimientos mecánicos, a veces en sentido inverso. La vida maravillosa se detiene. El niño, como el pueblo que sitúa las Tullerías, hace un esfuerzo supremo; por último lo entreabre, él es el más fuerte. ¿Pero dónde está el alma? Aquí comienza el estupor y la tristeza." Baudelaire, Charles: Moral del juguete, en Salones y otros escritos sobre arte, Madrid, ed. Visor, 1996, pp. 195 - 196.

${ }^{28}$ Didi-Huberman, George: La invención de la histeria, Charcot y la iconografía de la Salpêtrière, p. 12.

${ }^{29}$ Idem.
} 
En esto radica que a pesar de su suntuosidad teórica, la psiquiatría positivista sólo atine a darse de cara contra la cosa misma. Como si llegara a la conciencia solamente a través del infortunio como quiebre en la confianza de un saber que fracasa, inevitablemente, al pasar a la acción. Si Ramos Mejía accede, sin embargo, al néctar enfermizo de la locura es porque trasciende, más allá de lo que él mismo puede entrever, la limitación de la posición positivista y se adentra en la escucha de una voz obscena que le viene de dentro para hipnotizarlo y arrojarlo, por el extravío de una cautividad fascinada, a la ciénaga infesta del decadentismo. ${ }^{30}$ El mismo Huysmans marca la pauta sobre el inevitable fracaso de una ciencia que neciamente cree haber conjurado a todos sus demonios. "Cuando uno reflexiona sobre este tema, dice Huysmans en Là-bas (1892), el aplomo de los positivistas resulta desconcertante. Decretan que el satanismo no existe y ponen todo a cuenta de la histeria aguda, mal que, por otra parte, desconocen por completo, en su naturaleza y en sus causas. Sin duda, Charcot puede determinar muy bien las fases del acceso, registrar las actitudes ilógicas y pasionales de la enferma, así como sus movimientos de payaso; puede descubrir las zonas histerógenas y, ejerciendo presión sobre los ovarios, graduar la velocidad de la crisis. Pero en cuanto prevenirlas y conocer sus causas, en cuanto curarlas, ¡nada! Todo lo que se intenta fracasa con esta enfermedad inexplicable, pasmosa, que suscita las interpretaciones más diversas sin que ninguna de ellas pueda considerarse adecuada."31

Como deja entreverse en el enunciado de Huysmans, la cosa solo puede suscitar interpretaciones. Y si asistir a la irrupción de la cosa solamente resulta posible en tanto que inventores, aquello que Ramos Mejía demuestra en acto en su escritura, es la pregnancia de la hipocresía como método. La "histología de la historia" en cuanto discurso biológico fetichizado pretende salvar al sujeto de su ruina inevitable, extraerlo en un arbitrio injustificado de todo contagio y parentesco con la locura. El aplomo imperturbable se sustenta en la fantasía de coexistencia que cree poseer respecto de la

\footnotetext{
${ }^{30}$ Horacio González nos acompaña respecto de esta filiación. "Cierto, se cree positivista, darwinista, biopatólogo social. Pero en realidad es un escritor del decadentismo, tras la estela de novelas como $A$ contrapelo (À Rebours, 1885), de Huysmann, donde su personaje Des Esseintes pone una mirada aristocrática para percibir el grado de locura y fina destrucción que implica el mero paso del tiempo." González, Horacio: José María Ramos Mejía: terror, locura y misticismo, p. 11.

31 Iglesias, Claudio: Prólogo e introducción a Antología del decadentismo, perversión, neurastenia y anarquía en Francia, 1880 - 1900, Bs. As., ed. Caja Negra, 2015, pp. 58 - 59.
} 
verdad entendida como reino esotérico de las causas ocultas. Pero ¿acaso su verdad no resulta otra cosa que olvido? Como enuncia Nietzsche: "las verdades son ilusiones de las que se ha olvidado que lo son, metáforas ya utilizadas que han perdido su fuerza sensible, monedas que han perdido su imagen y que ahora entran en consideración como metal, no como tales monedas." 32 Cuando cae esta omnipotencia, la locura deviene experiencia de escritura para un sujeto que nace en el vacío abierto por su misma enunciación. En el artificio la locura accede, sin embargo, a su verdad. Verdad heterogénea respecto de aquella trivial hipocresía en la que se finge tener aquello de lo que se carece. Pero, a pesar de todo, verdad del hipócrita, de aquel que pone el cuerpo para hacer la experiencia dramática de lo verdadero en sí mismo. Por lo tanto, verdad indiscernible de la invención, inseparable de una puesta en escena, entonces, no opuesta necesariamente a la simulación. Pues hipocresía nombra "el desplazamiento equívoco, Verstellung, de la conciencia íntima de una verdad fingida a la asunción delante de todos de una simulación de verdad -y el desvío de ese desplazamiento mismo." 33 Hipócrita es entonces quien realiza un acto de juicio, decisión, elección, quien discierne, separa o distingue lo que está debajo $(v \pi o)$. Es el que da respuestas, el intérprete de sueños o de la palabra oracular. Adivino y terapeuta, es también y fundamentalmente el actor (hypokrites). "La hipocresía es el arte griego, el arte clásico del teatro; recitar lo verdadero empleando medios escénicos, es decir, hechos, contrahechos y simulaciones, de la respuesta interpretante." ${ }^{34} \mathrm{Si}$ tal como afirma Horacio González, los actos de escritura son en Ramos Mejía una misma cosa con la locura, es porque éste realiza, tal vez a su pesar, la herejía más aberrante, la de prestar una máscara escritural a la voz abismal y ominosa de la locura.

\section{4. Las multitudes en la historia.}

"En todas las cosas, el poder de lo infinitamente pequeño es formidable." 35

Como hemos observado en los apartados precedentes, la significación del desequilibrio psíquico no resulta algo unívoco ni susceptible de ser despachado rápidamente recurriendo a la supuesta eficacia de las categorías al uso. Como sucede

\footnotetext{
${ }^{32}$ Nietzsche, Friedrich: Introducción teorética sobre la verdad y la mentira en sentido extramoral, en El libro del filósofo, Madrid, ed. Taurus, 2000, p. 91.

${ }^{33}$ Didi-Huberman, George: La invención de la histeria, Charcot y la iconografía de la Salpêtrière, p. 16.

${ }^{34}$ Ibid., p. 17.

${ }^{35}$ Ramos Mejía, José María: Las multitudes argentinas, Rosario, ed. Biblioteca, 1974, p.224.
} 
con todo ensayista de talento, la escritura se resiste a ser domesticada bajo nebulosas normatividades, por el contrario, permanece siempre irreductible e indómita en su anómala rareza. "La literatura de Ramos Mejía actúa fuera de los límites reconocibles y lleva a inquisiciones de gran radicalidad sobre el conocimiento, la escritura y el fragor de la historia." 36 Esta intrínseca anomalía junto a esa rebelde agonística con la que busca medirse permanentemente con el enigma, no son, por lo demás, los únicos elementos que lo ligan a Sarmiento. Como éste, aquel es "un hombre del Orden fascinado con el desorden mental." ${ }^{37}$ Esa propensión al desequilibrio tampoco se limita a la sola iridiscencia de la enajenación individual, por el contrario, ella retorna en su bárbara potenciación, como la esencia sulfurosa de la multitud.

Un eco tardío de la crítica a la historiografía tradicional como edulcorada imagen del héroe viene a confluir con la reivindicación de la multitud. Esta última, en tanto que fenómeno plural, representa para Ramos Mejía el nuevo objeto patológico en el que se desenvuelve el acontecer histórico a la luz de su consciencia hechizada. "La función de la plebe argentina es tan importante como vaga y obscura todavía. La hemos condenado sin oírla, mal aconsejados por ese antropomorfismo histórico-político, que nos obliga a asimilar a una persona o figura histórica exclusivamente, las fuerzas ciegas que discurren en las entrañas de la sociedad y que cumplen su destino sin odios ni cariños." 38 La amoralidad de las "fuerzas ciegas" que horadan las "entrañas de la sociedad", deviene el equivalente sociológico de aquellas causas ocultas a las que se apela para vislumbrar el rictus macilento del aparecer exterior de la locura. Si a partir de las neurosis, Ramos Mejía pretendía instalar una "psicopatología del Estado" o una "Psiquiatría del Estado" capaz de descifrar el trascurrir equívoco de ese objeto enfermizo de la identidad nacional concebido en la intercepción de locura, política y temporalidad histórica, ahora lo que se pretende instituir para ese fin es una Microbiología de Estado con base fisiológica como correlato de una incipiente sociología de los fenómenos masivos.

Pero esta transposición está sujeta a las mismas influencias que su discurso sobre la locura. En primer lugar, al igual que ella, la multitud aparece como una figura del pharmakon. Si el trastorno psíquico aflora como indeciso crepitar entre enfermedad y

\footnotetext{
${ }^{36}$ González, Horacio: José María Ramos Mejía: terror, locura y misticismo, p. 11.

${ }^{37}$ Ibid., p. 17.

${ }^{38}$ Ramos Mejía, José María: Las multitudes argentinas, p. 24.
} 
genialidad, el acto de la multitud, análogamente, desencadena también consecuencias extremas y opuestas. "Como ya lo ha dicho la Fisiología: favorables o nocivos, según la circunstancia de su empleo, medicamentos o venenos, según su dosis, tal es la función de los virus conocidos, tal es también, como trataremos de demostrarlo, la de las multitudes en la historia del Río de la Plata." 39 En segundo lugar, a diferencia de la locura, la multitud -que si bien aparece como ella bajo el espectro de un objeto que obnubila por su ambigua atracción fascinante- se le muestra en la distancia helada que el ironista mantiene respecto de las mutaciones disparatadas que percibe o cree percibir en la fisonomía grotesca de la naturaleza. En este caso no le está permitido a la fascinación transgredir los límites que tienden a fundirla con su objeto. Un abismo de clase interrumpe cualquier confusión entre el intérprete y lo interpretado. La escucha de la locura se correspondía con una experiencia de la desmesura convertida inmediatamente sobre el cuerpo en escritura mórbida y autosacrificial, por el contrario, la de la multitud se asemeja al aislamiento contemplativo de una mística maldita cuyo objeto, de una heterogeneidad irreductible respecto del sujeto, invita a un consumo distante y sin contacto. Atracción inscripta en un espasmo de rechazo. Ídolo al que un interdicto irrevocable prohíbe tocar.

En la interpelación acerca de la multitud, se despliega la definitiva concentración en torno al infinito poder de lo pequeño, que se mantenía, por lo pronto, eclipsado por la figura del hombre superior. Entre Las neurosis y Las multitudes argentinas la heterogeneidad no se limita a la sola complejidad plural del segundo objeto. Como en un guante tomado por su reverso, el objeto multitud amerita ser abordado bajo el hormiguear vertiginoso de un pleamar anónimo que llega a la luz en configuraciones confusas y heterogéneas, según sea su situación particular en un instante temporal de irreductible singularidad. Le cabe al escritor descifrar cada intervalo significativo para extraer de allí, el cristal en bruto de su novedad que por esa vía accede, entonces, a la salvación en la conciencia. La multitud, objeto amorfo e impreciso por naturaleza, emerge de un fondo efervescente de furiosa temporalidad y cataliza cierta consistencia en el rechazo o la rebelión que en un instante circunstancial -superficialmente azarosola delimita respecto de la autoridad de turno. Desde esta perspectiva, el carácter célebre del líder queda supeditado al reflujo inmanente de las fuerzas acéfalas que crean a su meneur con el mismo ímpetu ciego que las impulsa tenazmente a constituirse en cuerpo

\footnotetext{
${ }^{39}$ Idem.
} 
homogéneo. Cuerpo opaco burilado en las singulares circunstancias concretas de cada medio histórico, político y social.

La apelación a la fisiología, al lenguaje "bio-metafórico" que encuentra pasadizos ocultos entre el microscópico cosmos viral y los fenómenos masivos a gran escala, se inscribe en el marco de la fetichización del discurso biológico. Es, por lo tanto, un índice decadente de la obtusa pretensión de fundar una ciencia de los fenómenos políticos y sociales susceptible de reducirse a un formalismo procedente de las ciencias naturales. Según esta pretensión, lo que vincula a la multitud con las formas más básicas del sustrato vital es la evolución, cuyas leyes generales promueven una continuidad fantástica y englobante que enlaza una a una las especies naturales con la gris indiferencia de un automatismo maquinal. ${ }^{40} \mathrm{La}$ "futura república" preexiste en el desarrollo de ese plasma germinal de la identidad nacional que evoluciona en forma análoga a "como del reptil salió el pájaro altivo en las edades remotas de la vida, el noble caballo del hipparion de tres dedos y éste, a su vez, del deforme arquiterium." ${ }^{41}$ La evolución o el progreso devienen el fantasma de una racionalidad que se desentiende, hasta donde puede, de la bizarra coalescencia de lo precoz y lo tardío, de lo preformado y lo pútrido que coexisten en el tiempo, cosa que, por otra parte, ella misma proclama en el cuerpo de una retórica ostentosa que destila un refinamiento desconcertante y seductoramente barroco. ${ }^{42}$

\footnotetext{
${ }^{40}$ Pero debe tenerse presente que el concepto de evolución que aquí se manipula es una traslación salvaje e injustificada de la doctrina darwinista al ámbito de la realidad social y cultural. "Resumiendo estas ideas, digamos que, en El origen de las especies (1859), Charles Darwin postuló una ley general según la cual las especies vivientes luchan por la supervivencia, y triunfan aquellas que mejor se adaptan al medio. (...) A esto se lo llamará «evolución» de las especies, término que al cruzarse con la idea entonces dominante de «progreso» suelen inducir a error. Porque la teoría darwiniana habla de «adaptación» y no de progreso, y nadie puede demostrar que los más adaptados sean superiores a quienes no pudieron adaptarse.” Terán, Oscar: Historia de las ideas en la Argentina, diez lecciones iniciales, 1810 - 1980, pp. $139-140$.

${ }^{41}$ Ramos Mejía, José María: Las multitudes argentinas, p. 35.

${ }^{42}$ Resulta significativo que la identidad nacional sea comprendida como la coalescencia anacrónica de atavismos y prefiguraciones virtuales que precisan, sin embargo, de un centro que unifique la multiplicidad implícita al desplazamiento de la multitud. "La personalidad nacional está en vías de formación cuando, como en el individuo, todo ese conjunto de sensaciones orgánicas, que parten de todos los puntos del cuerpo, han ido adquiriendo suficiente fuerza para llegar al sensorium y dar, por el
} 
Todavía en Ingenieros el registro sociológico encuentra su fundamentación en un concepto de evolución cuya etiología proviene de la ciencia natural. Aunque su lenguaje se muestre más escueto y mesurado que el de su maestro, no por eso, se torna menos inquietante. "Las «sociedades» humanas pueden estudiarse con el mismo criterio que los naturalistas aplican al estudio de otras «sociedades» animales; numerosas especies viven en grupos o colonias, no siendo imposible que los «homínidos» vivieran de esa manera antes de transformarse en «hombres», lo que excluiría todo hipotético contrato social." ${ }^{43}$ Como en Ramos Mejía, el encandilamiento cientificista borra la especificidad humana manifiesta en lo político que queda, por lo tanto, reducido a un grosero concepto sociológico ideado sobre la base de la mera asociación en clave biologizante. La predominancia del concepto genérico de asociación priva a lo político de su fundamento en el salto convencional del contrato y naturaliza los vínculos bajo el espectro homogeneizante del continuo vital, percibido ahora, como el resurgir iterable de una nueva armonía preestablecida. ${ }^{44}$ Las naciones o agregados humanos, dice

sentimiento del conjunto, una noción de unidad que se viene dibujando, o sea el sentimiento de una nación como en el individuo el de un cuerpo, el de una persona." Ibid., p. 61.

${ }^{43}$ Ingenieros, José: Sociología argentina, Bs. As., ed. Losada, 2013, p. 15.

${ }^{44}$ Como resulta conocido, en la concepción clásica de la política de tradición aristotélica lo político se opone a la asociación, como la koinonia politike lo hace respecto de la koinonia symmachia. En Aristóteles la política es praxis, por lo tanto, inseparable de la ética como doctrina de la vida buena. Es heterogénea con la ciencia y la techné, y jamás se reduce a la asociación. Esta confusión se origina según Habermas en la interpretación tomista de la letra aristotélica. "El involuntario distanciamiento respecto de la antigua política no se muestra en ninguna otra parte de una forma más precisa que en la traducción textual del zoon politikon: «Homo naturaliter est animal sociale».” Habermas, Jürgen: Teoría y praxis, estudios de filosofía social, Madrid, ed. Tecnos, 2012, p. 55. La asociación no puede ser política porque a diferencia de la praxis que tiene un fin en sí misma, toda asociación se constituye en función de un fin externo, incluso ilícito. "Más que cualquier elaborada teoría, esta inconsciente sustitución de lo social por lo político revela hasta qué punto se había perdido el original concepto griego sobre la política." Arendt, Hannah: La condición humana, Bs. As., ed. Paidós, 2011, p. 38. Pero incluso una teoría política contemporánea que pretenda revalidar la especificidad de lo político no puede, sino que desacreditar la primacía del concepto de asociación. En Carl Schmitt, por ejemplo, lo político que no se reduce a lo moral, estético o económico, posee la dimensión de un acto que decide sobre las instancias secundarias que se le supeditan. Es el salto decisivo lo que fundamenta todo orden o principio asociativo que mantendrá su vigencia, mientras esa decisión no resulte contradicha o sustituida. De ahí que el Estado, como paradigma de ordenación cooperativa, siempre presuponga lo político. Cf. Schmitt, Carl: El concepto de lo político, Madrid, ed. Alianza, 2009. 
Ingenieros, como las "colonias animales" y las "colonias microbianas" se "organizan de acuerdo a las condiciones de subsistencia propias de la especie". ${ }^{45}$ En el enunciado de Ingenieros, aún permanece un resonar latente de las palabras de Ramos Mejía que llamaba a hacer una historia política y social bajo la fantasmagoría de una historia natural. "Habría que hacer, y sería sugestiva, una historia de los encadenamientos políticos y sociales, como existe ya de los encadenamientos animales, (...) por ese mismo procedimiento veríamos cómo surgen las grandes ideas, a veces de un sencillo sentimiento que en el principio de la vida, apenas si es simple superstición en la conciencia del pueblo primitivo." 46 Pero, se distancia de él, en el hecho de que, aunque lo sociológico se fundamente en lo biológico, los agregados humanos muestran entre ellos una heterogeneidad irreductible producto de la adaptación a un medio físico que dista mucho de ser homogéneo. La adaptación al medio, entonces, tiene consecuencias en el artificio de las instituciones y en las creencias que afirma la colectividad. Ingenieros reconoce una especificidad sociológica que si bien se encuentra fundada sobre un sustrato biológico, no es susceptible de una completa inmersión en él, pues en la interacción con el medio el hombre lo transforma. "La evolución humana es una continua variación de la especie bajo la influencia del medio en que vive. Por ser una especie viviente, está sometida a las leyes biológicas; por ser capaz de vivir en agregados sociales, se subordina a leyes sociológicas, que dependen de aquellas; por ser apta para transformar y utilizar las energías naturales existentes en el medio, evoluciona según leyes económicas, especializadas dentro de las precedentes." ${ }^{\text {47 }}$ Estos agregados, además, deben adaptarse al medio en el marco de la "lucha por la vida" como "principio biológico" de la evolución humana. Finalmente, tanto uno como el otro, en sus diferencias y en concordancia con los fundamentos teóricos que comparten, son ciegos a la observación de un salto por el cual lo humano se constituye en la simultánea pérdida de su presunta naturaleza originaria, para vivir desde ese inicio en el tiempo de una equivocidad inacabable que hace que su existencia devenga indiscernible del artificio. No hay naturaleza capaz de sustraerse al silencioso procedimiento de esta invención. Es decir, al margen o fuera de toda representación que es siempre, representación para alguien. Para decirlo con Valéry, “(...) lo que se supone ya dado, ha sido, antes o

\footnotetext{
${ }^{45}$ Ingenieros, José: Sociología argentina, Bs. As., ed. Losada, 2013, p. 15.

${ }^{46}$ Ramos Mejía, José María: Las multitudes argentinas, p. 35.

${ }^{47}$ Ingenieros, José: Sociología argentina, Bs. As., ed. Losada, 2013, p. 16.
} 
después, producido. El pensamiento de que se captan las cosas en su originalidad es excitante; suele uno imaginarse que existe algo así como lo originario. Sin embargo, el mar, los árboles, el sol -hasta el ojo humano- todo eso es arte." 48 Como en Nietzsche, lo dado tiene el estatuto de metáforas muertas, monedas que valen como metal y no ya como tales monedas.

Pero incluso en Ramos Mejía, donde la analogía spenceriana entre organismo y sociedad es más visible (no así en Ingenieros que desacredita esta comparación), el anhelo de una sujeción última a leyes naturales capaces de imprimir un determinismo en clave biológica deviene inconsecuente e incluso contradicho como efecto del complejo y ambiguo espesor de su escritura. La lectura no se supedita solamente a lo dicho, sino también a lo no dicho o a aquello que en lo dicho se sostiene en forma enclenque y fallida, o sea, en el entredicho. Una ética de la lectura debe repensar estas supuestas nimiedades a las que tiene que atreverse a hacer justicia. Lejos de la imperturbabilidad que históricamente se promueve, el lector se actualiza en sus perturbaciones. Es en el resquebrajamiento y en la extrañeza donde se lee, como Horacio González confiesa respecto de Ramos Mejía, hacerlo desde su asombro. "Y ser justo consiste en asombrarse, como lectores, de las hondonadas que quiebran el argumento de un escrito y que en definitiva, revelan a un liberal que quiere serlo en la historia, mientras se lo impiden los mecanismos psíquicos que cree haber descubierto en el individuo y que lo atan a un oscuro romanticismo simbolista tanto como a un festejo estetizado del mundo natural." ${ }^{49}$ En Ramos Mejía asistimos a una escena de escritura donde las escansiones y arabescos que la constituyen potencian la equivocidad intrínseca de los significantes que encuentran, en ella misma, fragmentaciones y tensiones irreconciliables. En él, la ostentación y el vaporoso fasto, desdicen en acto el exclusivo interés científico de su discurso que estalla, finalmente, en sofisticación estética y cinismo político. Una disonancia espectral y marchita rechina como un susurro en su voz, vértigo que al interrumpir el continuo cientificismo de su discurso manifiesto, deja oír un encomio de lo deforme en el cuajo pestilente y obsceno de su delirio literario.

Esta tensión articula también su idea de multitud. Objeto que una literatura maldita construye a partir de la proyección del trastorno a escala monumentalmente

\footnotetext{
${ }^{48}$ Jauss, Hans Robert: Las transformaciones de lo moderno. Estudios sobre las etapas de la modernidad estética, Madrid, ed. Antonio Machado libros, 2004, p, 136.

${ }^{49}$ González, Horacio: José María Ramos Mejía: terror, locura y misticismo, p. 22.
} 
hacinada, y que la naciente sociología incorpora con un apetito voraz que la liga a ella casi como a su destino, irrumpe en Ramos Mejía entre la atracción y el terror o en la atracción del terror, en el abanico de tres registros simultáneos. En primer lugar, lo que se debe estudiar es "la multitud en sí, su organización, composición y papel en los diversos acontecimientos". En segundo lugar, "los hombres que proceden de ella, y son en toda su psicología, su expresión genuina, una proyección individual de su alma y su genio". En tercer lugar, "los dominadores de la multitud, los que, surgidos o no de ella, han tenido calidades de cierto orden que les ha permitido dominarlas, dirigirlas y, a veces, transformarlas." 50

En principio, el abordaje de esta estratificación se realiza bajo el amparo de $L a$ psychologie des foules (1895) de Gustave Le Bon. La preocupación y especulación por los fenómenos de aglomeración y saturación del espacio público por las masas es un desvelo de época que guarda ciertos rasgos semejantes en gran parte del mundo y que, además, trasciende a la sociología como disciplina específica. Toda una caracterización estigmatizante de la multitud comienza a prefigurarse a la luz de la puesta en cuestión del orden social vigente que el nuevo sujeto político realiza. Tanto el texto de Le Bon, como la colosal mutación arquitectónica de París que ejecuta la reforma del Barón Haussmann, son el efecto traumático de las revueltas de 1831 y 1848 que conducen a la Comuna de $1871 .{ }^{51}$

Como dijimos, la multitud está construida bajo la idea de una alienación colectiva. Como un ser nuevo que solicita el sacrificio de la racionalidad individual para poder inscribirse como miembro del mismo. Lo que Ramos Mejía toma de Le Bon es la representación de que esta incorporación exige una mutación que debe darse entre el registro de lo individual y el de lo colectivo. Transformación que promueve la existencia de un nuevo sujeto, "el alma de la multitud", como presunta identificación en el plano del sentimiento y la pasión de este ser plural. "En determinadas circunstancias,

\footnotetext{
${ }^{50}$ Ramos Mejía, José María: Las multitudes argentinas, p. 26.

51 “El verdadero objetivo de los trabajos de Haussmann era asegurar la ciudad contra las guerras civiles. Lo que quería era evitar para siempre que se pudieran levantar barricadas en París. (...) Y Haussmann quería impedir estas tácticas de dos maneras: el ancho de las calles las haría imposibles, y nuevos trazos de calles debían crear el camino más corto entre los cuarteles y los barrios de trabajadores. Los contemporáneos llamaron al proyecto «Гembellissem[e]nt stratégique».” Benjamin, Walter: París, capital del siglo XIX, en El París de Baudelaire, Bs. As., ed. Eterna cadencia, 2012, pp. 60 - 61.
} 
una reunión de hombres posee caracteres nuevos y distintos de los que individual y aisladamente tiene cada uno de ellos. Por una especie de abdicación de la personalidad consciente, que desaparece, diremos así, diluida y transformada, los sentimientos y las ideas de todos tienden a ponerse a un mismo diapasón, a caminar en una misma dirección, de tal manera que su organizado conjunto llega a constituir lo que se ha llamado el alma de la multitud, el alma colectiva, que, aunque transitoria, presenta caracteres bien netos y precisos." 52 La licuefacción de la racionalidad intensifica los sentimientos y las pasiones, la barbarie se contagia en el medio hiperconductor de una mímesis desbocada en identificaciones inconscientes. Pero, a su vez, esta fusión es siempre momentánea, volátil, provisional. Susceptible de permanente reconfiguración. La multitud funciona como un tóxico o como un centro enervado de seducción en el que se descargan incontenibles furores de sugestión. Es el narcótico cotidiano al que el flâneur se consagra con el propósito de superar el hastío en el olvido de sí mismo. Es la "inefable orgía", la "santa prostitución del alma" que se entrega, dice Baudelaire, "a lo que aparece de improviso, a lo desconocido que pasa". ${ }^{53}$

La alienación, la prostitución del alma en la orgía numeraria, es análoga a un arrobamiento por el que se pierde el contorno individual para sumergirse en la inconmensurabilidad ardiente del otro. En ese sentido, la multitud funciona como un símil de la locura, aunque suscripto a una situación provisional, es decir, transitoria en tiempo y espacio. "Hay en realidad una verdadera acomodación psíquica, lo que explica la distinta situación moral del individuo después que ha salido del encantamiento del contagio y de la sugestión que experimentaba dentro de esa prisión moral; si bien ciertas facultades están destruidas o disminuidas, otras se hallan exaltadas en un grado que rara vez se encuentra en el individuo aislado, lo que le permite lanzarse a cualquier acto con una impetuosidad que él mismo desconoce después que torna a su modesta situación de hombre común." ${ }^{, 54}$ Como bajo los rigores de la sugestión hipnótica, en la que se realizan actos que luego no se recuerdan o se lo hace con extrañeza, así el hombre de la multitud realiza sus extremas proezas. Las concreta, movido por fuerzas que lo gobiernan desde su invisibilidad, efervescentes impulsos a los que Ramos Mejía concibe como

\footnotetext{
${ }^{52}$ Ramos Mejía, José María: Las multitudes argentinas, p. 26.

${ }^{53}$ Baudelaire, Charles: Las multitudes, en Pequeños poemas en prosa, Madrid, ed. Cátedra, 2010, p. 66.

${ }^{54}$ Ramos Mejía, José María: Las multitudes argentinas, p. 27.
} 
provenientes de la vida refleja, allí donde reina el anquilosado refocilar del automatismo.

Pero, aquello en lo que Ramos Mejía se distancia de Le Bon, es respecto de la tesis de que todo hombre es susceptible de caer en estado de multitud. "Yo tengo mi teoría respecto de la composición de la multitud. Me parece que se necesitan especiales aptitudes morales e intelectuales, una peculiar estructura para alinearse en sus filas, para identificarse con ella, sobre todo. Difiero en eso de Le Bon y de otros, que piensan que puede constituirla aquel señor Todo-el-Mundo de que hablaba Bonet, cualquiera que sea su composición cerebral." 55 A diferencia de la locura, la multitud es objeto de un distanciamiento irónico circunscripto a un hiato de clase. Su materia prima es la masa, es decir, la serie numerada de los "elementos anónimos" que configuran, en los borbotones de su ligadura fáustica, el infinito poder de lo pequeño. "Individuos sin nombre representativo en ningún sentido, sin fisonomía moral propia: el número de la sala de hospital, el hombre de la designación usual en la milicia, ése es su elemento. El verdadero hombre de la multitud ha sido, entre nosotros, el individuo humilde, de conciencia equívoca, de inteligencia vaga y poco aguda, de sistema nervioso relativamente rudimentario e ineducado, que percibe por el sentimiento, que piensa con el corazón y a veces con el vientre: en suma, el hombre cuya mentalidad superior evoluciona lentamente, quedando reducida su vida cerebral a las facultades sensitivas." ${ }^{56} \mathrm{Si}$ el flâneur en su comercio con la multitud aún obtiene un ingrávido deleite como subproducto de un ergotismo urbano al que periódicamente se somete, el exclusivo desprecio que Ramos Mejía siente por ese elemento se lo impide por completo. Este exclusivismo lo acerca a esa mórbida sensibilidad que reposa en un refinamiento esnobista cuyo tinte aristocrático destila una melancolía que goza, a la distancia, de la pueril degradación. En forma análoga a Des Esseintes, el personaje de $\grave{A}$ Rebours de Huysmans, que amplifica en su caminar por las calles de París, el asco y el aborrecimiento hipocondríaco que siente ante la fauna degradada que se interpone efímeramente ante su campo perceptivo. "El simple roce con la cara de la gente, al pasear por la calle, se había convertido para él en uno de los más dolorosos suplicios." ${ }^{\circledR 7}$ El elitismo de Ramos Mejía esconde, a la vez que un evidente dogmatismo, dominio

\footnotetext{
55 Ibid., p. 30.

${ }^{56}$ Ibid., p. 31.

${ }^{57}$ Huysmans, Joris-Karl: a contrapelo, Madrid, ed. Cátedra, 2012, p. 146.
} 
político enmascarado bajo la fisonomía aséptica de una pseudociencia. El impersonal, el hombre sin más, aquel cuya individualidad transita sin gravitación alguna, contrasta, desde la inconsistente arbitrariedad a la que se habilita todo patriciado, con el ciudadano cuyo apellido acredita la sempiterna legitimidad del abolengo.

En este contexto, la multitud deviene la ocasión para que Ingenieros concrete su prorrogado parricidio. Ingenieros lee desde esa malevolencia que se justifica en una extrema cercanía $y$, por ello, con una pertinencia que pone la marca sobre ciertas inconsistencias que quedan, de ese modo, al descubierto, aunque su postura sea, en último término, tan cuestionable como la que se critica. En primer lugar, su crítica se sostiene como una demanda de severidad científica, por lo demás ausente, según él, no sólo en Ramos Mejía, sino incluso en todos aquellos que han manipulado injustificadamente tal concepto. Ni siquiera en Le Bon la "psicología de las multitudes" alcanza un umbral conceptual que la haga susceptible de diferenciarse de la "psicología social" o las "psicologías colectivas". Resulta imposible saber de qué se habla sin reducir, primero, esta confusión. El precepto según el cual hay una mutación entre el plano de las mónadas elementales y el complejo configurado por sus adiciones contradice el principio spenceriano del agregado social. Si esto es así, debería asumirse la heterogeneidad existente entre la "psicología social" y aquella que se ocupa de las multitudes, cosa que, no ha sido debidamente observada.

En Spencer la sociedad humana se suscribe el principio que enuncia que "los caracteres del agregado son determinados por los caracteres de las unidades que lo componen." 58 En este sentido, la relación entre los elementos y el agregado es de relativa homogeneidad y organicidad, por lo tanto: o el agregado social no es una multitud o ésta no se constituye a partir de una heterogeneidad entre los elementos y el conjunto. Este dilema lo resuelve Ingenieros precisando distinciones. La "psicología social" se ocupa del "conjunto de creencias y hábitos mentales comunes a los componentes de una sociedad" que cada hombre comparte por el hecho de vivir en la misma, de manera que, "adapta su personalidad a las creencias y costumbres de su medio." ${ }^{59}$ En tanto que la "psicología colectiva" se aplica a los problemas de la "raza, nación, casta, clase, profesión" y se encuadran bajo el principio spenceriano. Contrariamente, la "psicología de la multitud" se sustrae a la limitación de este

\footnotetext{
${ }^{58}$ Ingenieros, José: Sociología argentina, p, 93.

${ }^{59}$ Ibid., p. 95.
} 
principio. "La «psicología de la multitud», en cambio, es siempre una formación mental transitoria, cuyos caracteres difieren de los que se observan en aquéllas, es una forma atípica de confluencia mental entre los componentes de un agregado; mientras en las primeras la mentalidad colectiva es un producto de los caracteres individuales de los componentes, en la multitud fórmase un residuo diverso y aun contrario al de esos caracteres. $" 60$ Fundados en esta inobservancia Ingenieros enumera una serie considerable de contradicciones y absurdos en los que ha sido fértil el texto de Ramos Mejía.

Pero aquello que Ingenieros -posiblemente más allá de su deseo- señala, no se reduce a esta sola demolición de argumentaciones contradictorias y deficientes. Pues, como reverso de esta demanda de cientificidad que agita acaloradamente y como correlato de su propio prejuicio no percibido, Ingenieros pone el acento sobre ciertos elementos estilísticos de la prosa de Ramos Mejía que quedan, como suspendidos, entre la reprobación directa y la alabanza diferida. En una tesitura global de reproche, Ingenieros pretende conjurar el hechizo inmanente a la escritura de su maestro. "La obra de Ramos Mejía merece ser detenidamente analizada por lo mismo que aspira a tener proyecciones novedosas, sin dejarse sugestionar por ciertas elocuentes bellezas literarias con que el autor disfraza sus fundamentales lagunas científicas." ${ }^{61} \mathrm{Si}$ se nos permite, nos parece significativo invertir el signo de esta reprobación y leer, el llamado a poner entre paréntesis el poder de sugestión de la escritura, como si se tratara de un cumplido encubierto. En primer lugar, el enunciado de Ingenieros apoya nuestro interés de cuestionar la pertinencia sin resto de la categoría de positivismo para referirse a la escritura de Ramos Mejía. Ingenieros es quien involuntariamente nos apoya al huir despavorido ante un fraseo que rápidamente identifica como anómalo, extraño e inadecuado para la gris neutralidad requerida en una obra científica. En su rechazo, paradójicamente pone la marca en la sonoridad aberrante y en el fraseo lúdico y enfermizo cuya genealogía resulta por completo extranjera respecto de la gramática normalizada del cientificista.

En segundo lugar, esta anomalía estética va acompaña de una no menos escandalosa execración teórica. El espíritu "artista", que Ingenieros denuncia en Ramos Mejía, llega a su paroxismo en el abordaje histórico. La ausencia de método es suplida

\footnotetext{
${ }^{60}$ Ibid., pp. 95 - 96 .

${ }^{61}$ Ibid., p. 93.
} 
por una narrativa que más tiene de "fantasía" que de "ensayo sociológico". ${ }^{62}$ La arborescencia de sus construcciones, muestran un perfil híbrido. En él la imaginación socava la supuesta permanencia de los hechos que devienen inseparables de la ficción. Culminan, entonces, por desvanecerse en un pastiche que combina, la arbitraria unilateralidad y la capitulación del hecho a un apriorismo en el que insiste, más que lo observado, lo efectivamente deseado.

Pero, tal vez sea este exceso, el entusiasmo blasfemo que lo conduce irreversiblemente a sus defectos y desvaríos, aquello que retorna en su restallar actual, singularmente atractivo. "Ramos Mejía, en muchas páginas de su obra, abandona la serena imparcialidad del estudioso, unas veces para entregarse a los entusiasmos que sus multitudes le inspiran, y otras para juzgar con indudable parcialidad hechos y fenómenos que le son personalmente antipáticos." ${ }^{63}$ En todo caso, ya no se trata del eminente científico, se trata del perturbado, del sacrílego que acumula papeles en los que deposita las obsesiones que su objeto patógeno le dicta. Rarezas que irrumpen en el medio viscoso de una fascinación que alterna, discrecional y simultáneamente, la vindicación y el rechazo. "Cegado por el resplandor de su multitud" y para el desconsiento de Ingenieros, el escribiente conjuga, en un cuerpo deforme e inarticulado, su obtuso desprecio de clase con la euforia apologista del brujo, el nigromante, el adivino o el fraile apóstata. ${ }^{64}$ Finalmente, la extravagante idea de concebir una historia nacional bajo el espectro de una categoría sociológica concebida con el fin limitado de explicar el fenómeno sustancialmente europeo de las masas urbanas, deja los más inquietantes interrogantes. No asistimos en Ramos Mejía a un pensador que va a saldar sus cuentas con las preguntas. Tal vez jamás sepamos qué es su multitud, posiblemente ni él mismo lo haya sabido. Sólo permanece la estela brumosa de su desaparición. El drama teatral de su invención que es, simultáneamente, un mito de la identidad nacional. En esa superposición radica el interés. En los restos insistentes de una figura abyecta que sobrevive al hontanar de sus metamorfosis porque se consustancia, oscura y místicamente, con el devenir mismo de la historia.

\footnotetext{
${ }^{62}$ Ibid., p. 108.

${ }^{63}$ Ibid., p. 113.

${ }^{64}$ Ramos Mejía, José María: Las multitudes argentinas, p. 37.
} 


\section{II - El terror:}

\section{1. Terror e historia.}

El terror es el doblez cenagoso de la historia. Es el fondo violento desde el cual ella adquiere su primera determinación fetal, pero que, sin embargo, la acompaña desde entonces, como una noche indiferente, como una sombra pétrea en la que resuena el eco refractario del tiempo. En este sentido, el terror es aquello que necesariamente olvidamos, la inminencia amenazante del abismo meduseo que clama por resurgir para devorar, con su nocturnal garganta, la diáfana luminosidad de los trabajos y los días. Él es entonces, la cara oculta tras la mascarada de la civilización, su repliegue siniestro. Es la locura o la eflorescencia violenta de la multitud devenida imagen. Rigidez fósil, paradójica convivencia de heterogeneidades suspendidas. El resplandor hierático que condensa indisolublemente lo larval con la decrepitud. De ahí la fascinación indecisa por la zoología híbrida del pharmakon. "A fines del siglo XIX, los socialdarwinistas aplicaron los conceptos de la historia natural darwiniana a las discusiones en torno a la «evolución social». (...) La idea de «evolución» social en realidad glorificaba el ciego curso empírico de la historia humana. Proporcionaba apoyo ideológico al status quo, afirmando que el capitalismo competitivo expresaba la verdadera «naturaleza» humana, que las rivalidades imperialistas eran el saludable resultado de la inevitable lucha por la supervivencia, y que las «razas» dominantes se justificaban sobre la base de su superioridad «natural». Dentro de este discurso pseudocientífico, la denuncia de la injusticia social se transformaba en una imposibilidad lógica." 65 El terror habita esta imposibilidad, como un sordo alarido en los engranajes de la "evolución". Si bien olvidado, regresa en las excepciones malditas, en la furtiva barbarie que irrumpe en los intersticios para interrumpir la presunta «naturalidad» de los términos, revelando en un instante, la cínica hipocresía oculta tras el discurso civilizador.

Pero el terror es también, desde el interior mismo de este discurso civilizador, la otredad maléfica. La barbarie visceral que la racionalidad debe conjurar. El loco, la multitud, el inmigrante, el criminal, simplemente la otredad que marca esa negatividad inasimilablemente reticente para la civilización. Desde el punto de vista esencialmente político, el terror encapsulado en esta significación hegemonizada por los adalides del

\footnotetext{
${ }^{65}$ Buck-Morss, Susan: Dialéctica de la mirada. Walter Benjamin y el proyecto de los Pasajes, Madrid, ed. Antonio Machado libros, 2001, p. 75.
} 
progreso, aparecerá bajo dos perspectivas. En primer lugar, bajo la égida tradicional de superposición entre tiranía y barbarie. El gobierno de Rosas será descripto como el carnavalesco instituirse de la locura en gobierno. En segundo lugar, en la consustancial inherencia de terror y subversión del orden establecido. Locura, criminalidad y revolución constituyen, de este modo, la condensación misma de los fantasmas de toda una época.

\section{2. Terror y política.}

Como un resto de patetismo romántico, presente por lo demás en su imagen del genio y de la multitud, Ramos Mejía superpone lo sublime y la enfermedad. El parasitismo de lo elevado y lo bajo esfuma los bordes del trastorno, que en ciertas excepciones, irradia una salud superior. El problema de la locura en la historia es el de la incidencia de esta condensación en la idiosincrasia de nuestro ser nacional. Pero es también, la pregunta por el terror, entendido como círculo vicioso entre historia y locura. El azote de la locura es el origen de la crisis histórica, pero esto no invalida que la conflagración histórica sea también el origen de la perturbación psíquica. El reservorio bárbaro del hombre del desierto señalado antaño por Sarmiento, "imaginación viva y exaltada", natural tendencia a la poesía y a la música, deviene ahora "natural predisposición", que espera en latencia, la investida de la conmoción de los "acontecimientos políticos", para detonar, el veneno de las perturbaciones nerviosas por todas las venas del cuerpo social. "Los acontecimientos políticos desempeñaron un rol importante, sino en la producción de la locura, por lo menos en la patogenia de estos estados individuales enfermizos que se observan en ciertas personas ilustres, y aunque con menos acentuación en pueblos enteros."

El círculo del terror, como hemos visto, no solo determina al genio, sino que en ciertas ocasiones, se disemina en la multitud. Esta diseminación se sustenta en la analogía entre el pueblo y el organismo humano. "Lo que sucede en el organismo humano se observa también en el organismo social y político."67 El terror cumple entonces el lugar de "la palanca más poderosa" que recrudece los horrores al contagiarlos como la peste. En este sentido, un régimen del terror, como ha sido descripto tradicionalmente, bajo la primacía de la historiografía liberal, el gobierno de

\footnotetext{
${ }^{66}$ Ramos Mejía, José María: Las neurosis de los hombres célebres en la historia argentina, p. 169.

${ }^{67}$ Ibid., p. 185.
} 
Rosas, no podía sino que tener una influencia nefasta y formidable en la producción de excitaciones y estímulos mórbidos, cuyas consecuencias maléficas, cristalizan en susceptibilidades enfermizas que propagan las neurosis como si de una plaga se tratara.

No sorprende, entonces, que Ingenieros comente que bajo la tiranía de Rosas hubo exuberancia de alienados. "Nadie ignora que en las épocas de terrorismo político suelen aumentar considerablemente las perturbaciones mentales." ${ }^{68}$ En este contexto, el recurso a las causas ocultas del padecer psíquico se traslada subrepticiamente al terreno público sobre el fondo analógico de la relación entre cordura-orden y locura-desorden. El efecto de esta analogía será, por un lado, vincular la "cordura" al "orden público y a la estabilidad social", y por el otro, a la búsqueda de modulación "de los excitantes que acompañan la vida urbana civilizada." ${ }^{69}$ De ahí que la época de Rosas apareciera como la anamorfosis donde esta relación se proyecta como espectro deformado. Su gobierno es el mundo del revés, la apoteosis carnavalesca de una fauna rabelesiana. Pero ante todo, es la falsificación paródica del orden, por lo tanto, es el desorden devenido ley, la locura saturando con su ímpetu grotesco cada intersticio de realidad.

El entusiasmo delirado de Rosas arrastra hacia el cataclismo al conjunto de la sociedad que no puede, sino que adaptarse al arbitrio del disparate como modo de evitar un padecimiento seguro. Como en un drama barroco, el mundo deviene un theatrum mundi en el que lo infecto destila apariencia de pulcritud, al tiempo que prolifera la irrisoria pompa de dementes y bufones. "Don Juan Manuel de Rosas, como es frecuente en los tiranos, tuvo marcada afición a rodearse de locos bufones." ${ }^{~} 70$ Cada uno de ellos saciaba algún perverso particularismo de su "imaginación fosforescente". Desde la más vulgar lisonja a la más abrasiva diatriba política. Pues mientras algunos "le servían para alegrar el ánimo, otros para fastidiar a personas antipáticas, varios como agentes de propaganda política y no pocos en su complicadísimo servicio de espionaje."71 La inversión paródica del orden producto del rosismo, hunde al cuerpo social en un sueño cataléptico que permite tan solo dos formas atenuadas del despertar. En primer lugar, en la simulación de la locura, como ese Don Eusebio que "había descubierto que, siendo loco, podía pasar una vida más regalada que los orates del hospital, y, en ocasiones,

\footnotetext{
${ }^{68}$ Ingenieros, José: La locura en la Argentina, Córdoba, ed. Buena vista, 2005, p. 89.

${ }^{69}$ Vezzetti, Hugo: La locura en la Argentina, p. 102.

${ }^{70}$ Ingenieros, José: La locura en la Argentina, p. 90.

${ }^{71}$ Ibid., p. 91.
} 
divertida." En segundo lugar, en la identificación con el tirano. "El loco se había identificado con Rosas, a punto de adivinar, en una mirada, cuál de las personas presentes le era la más antipática, y sobre ello volcaba sus sátiras ofensivas.",72

El terror lo captura todo al sumergir al mundo en la locura. A través de la simulación y de la identificación, el tirano concreta su obra de inversión satírica, sometiendo al conjunto a un culto delirante que conduce las energías inconexas que exuda la anatomía de la multitud irreversiblemente sobre su persona. El lugar excepcional de Rosas en nuestra historia está marcado por ese carácter híbrido, por esa paródica androginia que hechiza multitudes y que desde Sarmiento se le concibe como ser paradójico y dual, la farsa misma de una totalidad sin fisura. "Facundo no ha muerto; está vivo en las tradiciones populares, en la política y revoluciones argentinas; en Rosas, su heredero, su complemento; su alma ha pasado en este otro molde más acabado, más perfecto; y lo que en él era sólo instinto, iniciación, tendencia, convirtióse, en Rosas, en sistema, efecto y fin. La naturaleza campestre, colonial y bárbara, cambióse en esta metamorfosis, en arte, en sistema y en política regular capaz de presentarse a la faz del mundo, como el modo de ser de un pueblo encarnado en un hombre que ha aspirado a tomar los aires de un genio que domina los acontecimientos, los hombres y las cosas. Facundo, provinciano, bárbaro, valiente, audaz, fue reemplazado por Rosas, hijo de la culta Buenos Aires sin serlo él; por Rosas, falso, corazón helado, espíritu calculador, que hace el mal sin pasión y organiza lentamente el despotismo con toda la inteligencia de un Maquiavelo."73 Rosas es para Sarmiento un travestido, el simulacro de una síntesis perfecta aunque herética de las tensiones históricas. Es el disfraz donde se pervierten los valores, duplicidad burlesca y blasfema que solo goza con ultrajarlos. Pues su ser es el terror, es decir, nocturno psiquismo surgido de la borradura de todo límite y de toda legalidad. Ni lo uno ni lo otro, he ahí su lema. Rostro abombado entre la evanescencia del mito y la gravitación de lo real ("Esfinge Argentino"). Punto indecidible entre tendencia y sistema, campo y ciudad, sueño y vigilia, hombre y mujer, humanidad y animalidad. Puede comprenderse entonces la ambigua fascinación que su espectro despierta en los pensadores de finales del XIX, el invertido bestial, sinécdoque y metáfora del terror y la locura. El "pletógeno bicéfalo (...) es casi un vertebrado, en el sentido de una final perfección en ese

\footnotetext{
${ }^{72}$ Idem.

${ }^{73}$ Sarmiento, Domingo Faustino: Facundo, Bs. As., ed. Terramar, 2007, p. 15.
} 
transformismo mental lleno de sorpresas; era, como dije antes, una expresión de las dos multitudes: de la multitud decrépita de la ciudad fatigada, y de la barbarie rural, exuberante de sangre oxigenada, de músculos espesos de troglodita, de nervios vírgenes y excitables." 74 Genio intermedio, mixto como la locura, monstruosa conflagración de violencia fascinante y de femenina sugestión, un centauro o "sirena simbólica: mitad gente, mitad animal, como informan los cuentos mitológicos que circulan alrededor del fogón". 75

Ahora bien, esto no impide, sin embargo, que bajo cierta coyuntura particular, el mismo Rosas pueda aparecer como la figura ideal del guardián del orden que se encuentra amenazado por el reverberar de los bárbaros. El Restaurador de las Leyes y del Orden, asoma a la fantasía febril de los pensadores de finales del XIX, paradójicamente, como un pharmakon ante el terror. En la dicotomía entre corduraorden y locura-desorden, Rosas cae como garante de las primeras, ante la emergencia de un mal mayor alucinado en la figura hostil del inmigrante como purulento elemento del fenómeno multitudinario. La emergencia de este nuevo agente del terror se observa en los últimos capítulos de Las multitudes argentinas, que Ramos Mejía dedica a las multitudes de los tiempos modernos. El desprecio elitista se conjuga en forma de refinamiento brutal. "Cualquier craneota inmediato es más inteligente que el inmigrante recién desembarcado en nuestra playa. Es algo amorfo, yo diría celular, en el sentido de su completo alejamiento de todo lo que es mediano progreso en la organización mental. Es un cerebro lento, como el buey a cuyo lado ha vivido; miope en la agudeza psíquica, de torpe y obtuso oído en todo lo que se refiere a la espontánea y fácil adquisición de imágenes por la vía del gran sentido cerebral."76

El vituperio se muestra como el reverso de una fascinación que se haya motorizada por un pavor crepuscular. La resignificación de la figura de Rosas se debe a que la multitud amenazante no es ya la de la montonera que habita en los campos, sino las multitudes urbanas. "De modo que las multitudes que «hacen problema» en el giro del siglo XIX al XX son ahora las multitudes urbanas, que en el caso argentino se hallan entremezcladas con el mundo de los trabajadores y, por ende, con la inmigración (dado

\footnotetext{
${ }^{74}$ Ramos Mejía, José María: Las multitudes argentinas, p. 202.

${ }^{75}$ Idem.

${ }^{76}$ Ibid., p. 208.
} 
que trabajador e inmigrante son categorías que en su mayoría se superponen)." ${ }^{, 77} \mathrm{El}$ inmigrante aparece ahora como un órgano exógeno y por ello, amenazante. Inquietante, puesto que es visto como el agente del desorden, de la conflagración anárquica y del delirio anónimo. Representa esa fuerza efervescente de lo pequeño y del número que busca exhibir los fundamentos ilegítimos del orden establecido, corroyendo su estructura hacia una adulteración que lo lleve finalmente a implosionar.

La desconfianza sobre las masas se fusiona con el horror al comunismo y al anarquismo, a toda esa importada sinergia de la insurrección que pulsa hacia la revolución. Desde la revolución de 1848, se produce en Europa toda una literatura que pretende exorcizar este mal. Un cortocircuito teórico entre el discurso médico y el político intenta fundar las bases de una interrelación entre locura y revolución. Después de una revolución, dice Ramos Mejía, lo que predomina es "el elemento nervioso, las alteraciones generalmente dinámicas y a veces pasajeras del centro encefálico". (Las neurosis, p. 168) La salud del cuerpo social depende de la prevención de este cataclismo mayor. El círculo de locura e historia se transfiere al discurso contrarrevolucionario como un nuevo círculo concéntrico en el que se fusionan revolución y locura. Lo que estimula la atención de Ramos Mejía es la "incerteza respecto a dilucidar si una revolución es locura de la historia, o la locura en la historia emerge de una revolución." 78

Pero como prevenir es siempre mejor que curar, lo que busca Ramos Mejía es postular un pharmakon susceptible de contrarrestar el poder satánico de la locurarevolución. Este actúa en tres registros simultáneos de neutralización del terror. En primer lugar, como intento de interpretar y conocer acerca del grosero imaginario de la multitud como un modo de gobernar su anquilosado espíritu. "Si esta caracterización de las leyes que rigen el imaginario de las multitudes resultara atinada, de ella se obtendrían precisas instrucciones acerca de la posibilidad de manipulación de las masas, ya que «el que conozca el arte de impresionar la imaginación de las muchedumbres conoce también el arte de gobernarlas»."79 En segundo lugar, apelando a la educación y a las costumbres locales como formateo de esa "dócil plasticidad" característica de ciertos inmigrantes. "Me asombra la dócil plasticidad de ese italiano inmigrante. Llega

\footnotetext{
77 Terán, Oscar: Historia de las ideas en la Argentina, diez lecciones iniciales, 1810 - 1980, p. 129.

${ }^{78}$ González, Horacio: José María Ramos Mejía: terror, locura y misticismo, p. 17.

${ }^{79}$ Terán, Oscar: Positivismo y nación, Bs. As., ed. Puntosur, 1987, p. 19.
} 
amorfo y protoplasmático a estas playas y acepta con profética mansedumbre todas las formas que le imprime la necesidad y la legítima ambición." ${ }^{80}$ La educación posee un poder fáustico y poiético capaz de producir un nuevo cuerpo construido sobre la base de la asimilación de todos los fragmentos exógenos, homogeneizados a partir del rigor nacionalizante de la liturgia patria. Finalmente, en tercer lugar, suturando el hiato abierto entre elite y muchedumbre por la intermediación de un meneur que reivindica un paternalismo que no oculta su filiación autoritaria. Que el terror sea lo contrario de la civilización no imposibilita, que en ciertos casos excepcionales y ante un peligro mayor, como sucede efectivamente con los virus, cierta dosis homeopática de barbarismo puede ser la salvación del Orden racional y civilizado. La revalorización de la figura de Rosas debe comprenderse como un pharmakon cuyo efecto es disuadir la ofuscación revolucionaria. Pues el gran peligro es ese magma emocional e imberbe que constituye el perfil de la multitud, y que por eso, la hace susceptible de demagógicas manipulaciones. Allí arraiga el gran fantasma de todo elitismo, prorrogar el día decisivo en que la multitud se organice bajo un meneur implacable que llame a la virulenta insurrección y a la santa destitución de la injusticia imperante. "También es cierto que en este gris achatamiento político e intelectual en que vive, con ese corte fenicio que va tomando la sociedad metropolitana, el corazón se halla oprimido por el estómago, y el cerebro por los intestinos: esta ciudad tiene demasiado hígado todavía para que pueda dar cabida a un ideal; temo que el día que la plebe tenga hambre, la multitud socialista que se organice sea implacable y los meneurs que la dirijan representen el acabado ejemplar de esa canalla virulenta que lo contamina todo." ${ }^{81}$

\section{III - La simulación:}

\section{1. La metamorfosis y el gusano.}

"Un hormigueo de grotesco, una mezcolanza de máscaras delirantes, una abigarrada bacanal de siluetas multiformes: esto es lo que aparece a primera vista." ${ }^{2}$

\footnotetext{
${ }^{80}$ Ramos Mejía, José María: Las multitudes argentinas, p. 210.

${ }^{81}$ Ibid., p. 242.

${ }^{82}$ Rousset, Jean: Circe y el pavo real. La literatura del barroco en Francia, Barcelona, ed. Acantilado, 2009, p. 14.
} 
La simulación es el éxtasis de las formas. Su enrevesada proliferación en el estallar de las apariencias, que deshacen en languidez, todo perfil de los cuerpos. Propagación de siluetas, de mascaradas delirantes que cultivan el engaño. Bella apariencia suspendida, inescindible del sueño o de la pesadilla. La simulación habita todo espacio superficial, allí donde los reflejos sustituyen a los cuerpos y el disfraz a la piel, como fulgor de una identidad esmerilada, en metamorfosis permanente. El fingimiento y el disimulo resultan su dominio, arte de lo transicional, flujo cegador donde se licúan los contornos. En este sentido, la simulación y la metamorfosis se despliegan en el reverso del terror. Si este último es detenimiento osificado, noche melancólica que se fosiliza en imagen, la simulación, por el contrario, es juego histriónico de eufórica luminiscencia. La polifónica sucesión de simultáneas temporalidades heterogéneas. Es, por lo tanto, el reino del atavismo, el umbral de retorno de la forma anacrónica que viene a reconfigurarse siempre bajo una nueva mímesis. La metamorfosis se extrae como consecuencia de la temporalidad inherente al darwinismo. Pues "para Darwin no hay especies fijas e inmutables creadas de una vez y para siempre, sino formas variables que se suceden a lo largo de millones de años". ${ }^{83}$ Ella es el efecto desquiciante de una sociedad leída a la luz de esta historia natural.

Bajo el registro de la metamorfosis, entonces, impera el equívoco. Lo que existe, nunca es sólo lo que aparece. El equívoco se declina en destino si no se es capaz de develar el proceso permanente, aunque momentáneamente invisible, que habita a la cosa y hace de ella, un flujo continuo. La mutante coalescencia de su estado germinal y de su acmé prefigurado. El colosal trabajo de interpretación radica en descifrar los signos reconstruyendo su submundo latente. Como cuando Ingenieros descubre, con el rabillo del ojo, un gusano escondido tras un copo de algodón. La nimia escena exhibe la zoología ambigua que exuda el simulacro. "Dentro del copo descubrimos un conducto, espeso y resistente, que difícilmente hubiéramos adivinado no desprendiendo el copo de la pared; dentro del conducto se aloja un gusano, el cual, mediante las dos extremidades de su cuerpo, se fijaba a la pared y la recorría, arrastrando consigo su curioso ropaje." 84 El copo es el disfraz con el que el insecto disimula su presencia ante posibles depredadores. Para el gusano, la apariencia ha devenido un arma, un medio más para

\footnotetext{
${ }^{83}$ Terán, Oscar: Historia de las ideas en la Argentina, diez lecciones iniciales, 1810 - 1980, p. 140.

${ }^{84}$ Ingenieros, José: La simulación de la locura en la lucha por la vida, Córdoba, ed. Buena vista, 2005, pp. $11-12$.
} 
asegurar su supervivencia. La simulación, dice Ingenieros, es "un medio simple y excelente de lucha por la vida" 85 . Pero esta clara asociación en el reino animal se torna alterada fantasmagoría cuando es proyectada, sin resto alguno, al ámbito político y social. En primer lugar, en la alucinada descripción de esa nueva fauna producto de las mutaciones bizarras que Ramos Mejía viene a denunciar como efecto indeseable de esa multitud adulterada por el proceso inmigratorio y la modernización social. Es el bestiario oscurantista de los simuladores del talento. En segundo lugar, en la condensación entre transformismo, locura y criminalidad operada por Ingenieros. "Entre el gusano disimulador de su cuerpo bajo un copo de algodón y el delincuente disimulador de su responsabilidad jurídica tras una enfermedad mental, debía lógicamente existir un vínculo: ambos disfrazábanse para defenderse de los enemigos, siendo la simulación un recurso defensivo en la lucha por la vida." ${ }^{86}$

\section{2. De los simuladores del talento.}

La preocupación por la simulación, como se ha visto, tiene su etiología en el discurso biológico de tinte darwiniano. La temporalidad de la metamorfosis es la de un torbellino donde se esfuman los contornos. En este contexto, la mímesis se comprende como una figura de la adaptación en el marco de la lucha por la vida. El camuflaje del gusano o la mimética asimilación del camaleón a su entorno, no poseen otro sentido que la pretensión de supervivencia. Movimiento ciego y amoral, la simulación combina, un "mimetismo ofensivo, destinado a sorprender a la presa", y un "mimetismo defensivo, utilizado para ocultarse de la vista del agresor (mimetismo de disimulo), para asustarlo mediante algún aspecto engañoso (mimetismo de aterrorización)". Pero también, un "mimetismo directo, cuando el animal que imita tiene un interés inmediato para adoptar el disfraz" y un "mimetismo indirecto, cuando, a consecuencia de alguna adaptación común o de una convergencia, animales pertenecientes a especies diferentes presentan en cierto modo «semejanzas profesionales»." 87

\footnotetext{
${ }^{85}$ Ibid., p. 12.

${ }^{86}$ Idem.

${ }^{87}$ Caillois, Roger: El mito y el hombre, México, ed. Fondo de cultura económica, 1998, p. 95.
} 
Pero esta claridad conceptual se opaca, cuando en franca sintonía con los desquicios del darwinismo social, Ramos Mejía y luego, Ingenieros, transfieran estos principios como claves hermenéuticas para la interpelación de la nueva escena social. El mundo de la simulación deviene así un teatro pagano en el que los guardianes del orden aguzan sus sentidos con el fin de olfatear la obscena molicie que se esconde tras el resplandor de las apariencias. Lo que se muestra primariamente descriptivo en su aplicación al reino animal, trasmuta en discurso policíaco y moral. Pero ante todo, en palabra embrujada, prendada a su objeto por infinitas inervaciones obsesivas que la mantienen cautiva, a la espera de un control que fantasea con la plena neutralización de toda hostilidad. En este sentido, el dominio de la simulación es la hipérbole de la hipocresía. Como en un juego de corte o escena barroca, resulta imposible distinguir a la persona del personaje. Juego helado y estratégico en el que nadie puede sustraerse al riesgo que expone a todo depredador, por infortunada ocasión, de convertirse en la próxima presa.

Ramos Mejía aplica esta mirada al referirse al problema particular de las multitudes modernas. Tema de los dos últimos capítulos de su libro sobre las multitudes. En ellos libera su ingenio malevolente y exótico en la clasificación despiadada de esa "pequeña fauna" de anfibios y bicéfalos que son el efecto indeseado del enmarañamiento del medio producto de la inmigración y de la modernización social. Al lado de los leones y los elefantes, dice Ramos Mejía acudiendo nuevamente a la analogía zoológica, subsiste una pequeña fauna que los parasita, carroñeros que incapaces de suministrarse el alimento, subsisten con los desperdicios que abandona el cazador. Existe, de igual modo, en la sociedad, todo un submundo de desviados especímenes que sobreviven por su camuflaje, desplegando su talento hipócrita con fines exclusivamente defensivos. Éstos, por la apelación a un mimetismo consecuente, buscan aparentar lo que no son, disimulando a los ojos del otro, su raquitismo psíquico y moral.

Al desplazar el disimulo y la simulación del talento al registro defensivo, Ramos Mejía lo contagia de una connotación moral (aunque no moralizante) como denuncia de una cierta astucia preservativa de los impotentes. En analogía con el parásito, esta "pequeña fauna" desarrolla ciertas aptitudes, pensadas por lo demás como astutas artimañas, conductas caprichosas que cobran sentido únicamente con vistas a la lucha por la vida. "La función de la coraza con que la naturaleza ha dotado al crustáceo, la 
acción eficaz del movimiento, el alcance trascendental del disfraz cromático, estarían aquí reemplazados por el uso de una o muchas aptitudes, por el despliegue de facultades y procedimientos puramente mentales creados y perfeccionados por él, los peligros frecuentes y el juego trascendental de los instintos alarmados." 88 Como el crustáceo, ciertos hombres menores han desarrollado estrategias en el "orden psíquico" susceptibles de retribuirle beneficios en el orden existencial. Una peculiar paradoja, por lo demás observada por el mismo Ingenieros, se encarna en esta suspicaz identificación de astucia y raquitismo psíquico que Ramos Mejía cree percibir en la estructura del simulador. "Estos hombres mediocres ó inútiles, que son la expresión humana de aquella animalidad defensiva, tienen en su espíritu, como los paralíticos y los mudos en su cerebro, suplencias de extraordinaria aplicación; dón de espera del batracio oportunista, las trasmutaciones de la forma, el uso del color, las aptitudes, las complicadas comedias de todo lo que hiere el sentido alerta de sus enemigos. Todo ello no les sirve para agredir, sin embargo, porque la iniciativa es propiedad del talento como la fecundidad de la vida, pero se defienden con armas cuyo uso y mecanismo ignora aquél, porque es inocente y sin malicia frecuentemente." ${ }^{89}$ Ramos Mejía enlaza de forma compleja y arbitraria, por un lado, la mediocridad con una aptitud defensiva que cataliza en la afectación hipócrita del oportunista, y por el otro, cierta superioridad de hecho e incuestionada que se legitima en una autenticidad activa que es vista como el brotar mismo de un exceso vital indiscernible de la inocencia. De ahí que, el talento impostado devenga un verdadero pecado de clase. ${ }^{90}$ Es el pie ortopédico o la prótesis suplementaria, un artefacto cuyo fin es disimular una malformación congénita.

\footnotetext{
${ }^{88}$ Ramos Mejía, José María: Los simuladores del talento en las luchas por la personalidad y la vida, Bs. As., ed. Félix Lajouane, 1904, p. 3.

${ }^{89}$ Ibid., p. 6.

${ }^{90}$ El simulador es retratado como "macaneador", tramposo y ventajero, como un hypocrites, es decir, alguien que permanentemente se inventa a sí mismo. Los simuladores “(...) sugieren, sólo con sus actitudes falaciosas, la misma sensación, pero con completa ausencia de la fuerza efectiva; son los atletas del circo, cuyos pintados deltoides hacen prodigios de destreza sobre las balas de madera que imitan el duro hierro. Tienen en el espíritu todos los elementos de la ilusión y un dispositivo teatral por medio del cual, combinando simples manchas, dan en el lienzo la sensación completa de cosas que á la distancia resultan acabadas; con la escoba sugieren la sensación de un hombre, con un diario una bandera, con el bastón un cetro, y si el público tiene cierta disposición que las preocupaciones y el interés de otro ha suscitado, resultan: estigmas de la gloria las erupciones, cicatrices los traumatismos y rastros de la vigilia estudiosa las orejas libertinas de la mala noche.” Ibid., p. 14
} 
Resulta asombroso y por qué no también risible, la preocupación que este grupo de intelectuales manifiesta por la escena del fraude. El hermeneuta del fraude ajeno parece estar motorizado por su propio desconocimiento, encontrando signos en el otro que no son más que sus propias suplencias, es decir, reflejos por él omitidos. Entonces se dedica a rastrear la paja en el ojo ajeno y lo hace convencido de la licitud de sus actos, pues el fraude es un secreto compartido por un nosotros que se identifica inconscientemente con la nación. En este sentido, se puede decir irónicamente que redunda en el bienestar de todos. El escándalo ante la simulación, debe leerse en la fractura de esa imagen fascinante que representa la multitud para Ramos Mejía. Como hemos dicho, ésta encierra un poder ambivalente, como un arcaico fetiche, que promueve los sentimientos más extremos y encontrados. De ahí que la multitud pueda ser, en un momento, el elemento en el que se despliega la idiosincrasia nacional en el seno de la fermentación histórica, y en otro, sin aparente contradicción, la alteridad abyecta e infame de una clase que se ve a sí misma, como el baluarte y reservorio de los auténticos valores nativos. Por eso, el ordinario efecto de la simulación en el mundo natural, deviene perverso polimorfismo en la sociedad contemporánea. La agitación de la simulación permite inocular el veneno de aquellos que sienten, por primera vez, comprometida la mantención de su hegemonía presuntamente incuestionable. Paradójicamente, y más allá de todo aquello que los implicados estén capacitados para aceptar, el recurso a la simulación debe comprenderse, en ellos, como un giro más de la misma simulación que por lo pronto resulta inconfesable, ya que de lo contrario, deberían admitir su estrategia vejatoriamente defensiva. Pues si la simulación se inscribe en la crisis de la ciudad señorial, es porque esta crisis es percibida como una invasión de los bárbaros, como el burbujear amanerado de infames y enfermizos, pues son ellos los que pueden impunemente simular, el agente del número, aquel cuya principal arma es el anonimato, apellidos de sonoridades ininteligibles que evitan cualquier referencia inequívoca dentro del cosmos ordenado del status social.

De ello se desprende el dispositivo retórico visible en los textos de Ramos Mejía que, por lo pronto, se ve intensificado hasta el paroxismo en los dos últimos capítulos de Las multitudes y en Los simuladores del talento. Este dispositivo se ejerce como perfil irónico y socarrón que no duda en desplegar un "humorismo activo" e hiriente, pues goza de su altivo desprecio. Más allá de esa presunción de inocencia como mera "fecundidad de vida" que Ramos Mejía vocifera para los de su clase, es sabido que no 
existe, en modo alguno, literatura inocente. Incluso lo más significativo del valor literario de sus escritos se produce cuando ese fumismo refinado y decadente se ve excitado por un interés inconfesable, y logra liberarse de la morigeración cientificista que lo constriñe. El develamiento de la simulación como sarcasmo permanente se inscribe en ese movimiento descrito por David Viñas que va de la causerie al titeo en el teatro de Gregorio Laferrère. La innovación de Ramos Mejía es haber sublimado el titeo elevándolo hacia el género del ensayo. En primer lugar, el titeo es un signo de clase, ritual del gentleman y del clubman, registro exclusivísimo de un dandismo vernáculo. Un juego de corte que ejerce violencia suspendida, siempre contenida en el espesor jovial de las apariencias. Su despliegue consiste en "saber herir la fibra sensible, en despertar suavemente el sentimiento de vanidad que dormita en el fondo de todos los corazones, y al ofrecerle de acuerdo con las tendencias peculiares de cada espíritu un objetivo capaz de estimularlo... ir después despacio, preparando el ambiente propicio para su desarrollo, teniendo cuidado en evitar sacudimientos bruscos que alarmen la razón." $" 11$ El titeo requiere siempre de la táctica, es un esgrima de la palabra cuyo objetivo es "penetrar en el otro por su fisura más visible", "por su lado flaco" o por sus "debilidades", esperando el momento indicado para concretar el ataque asesino en el que se vencen, finalmente, todas las resistencias del oponente. "Procedimiento de ablandamiento, «enfermándolo» al otro en su peculiar enfermedad, de manera de conseguir una absorción de los controles en la zona más inerme «hasta que llega un momento en que podes a mansalva asestar el golpe de gracia con absoluta impunidad» ${ }^{\prime 92}$ En segundo lugar, el titeo es del orden del artificio y de la farsa, de la escena social como extensión de la teatralidad y viceversa. En Laferrère se da el desplazamiento del "titeo teatralizado" a la "función teatral del titeo" y esta teatralización generalizada se concreta en el marco de la crisis de la ciudad señorial que se ve asaltada por el fatigoso avance inmigratorio y cosmopolita. Por eso, es la observación, el ataque psicológico, aquello de que se goza al exponer al otro al ridículo, lo que otorga hilaridad a la pieza.

Ahora bien, esta teatralidad en la que se dramatiza el espíritu burlón junto a la violencia sobre el burlado, invita como toda teatralidad a una observación participante, es decir, jamás meramente pasiva. Al culminar la obra uno siente la responsabilidad de

\footnotetext{
${ }^{91}$ Viñas, David: Crisis de la ciudad señorial, Bs. As., ed. Corregidor, 2004, p. 93.

${ }^{92}$ Ibid., p. 94.
} 
haber asistido, como elemento necesario, a la mofa insensible de la "imperfección física" o de la "deformidad moral". Este sentimiento es por demás evidente en los escritos de Ramos Mejía. Con él concurrimos a un titeo generalizado cuyo objeto es esa nueva fauna de seres deformes a los que describe con una libidinosa malicia que es incapaz de disimular. Seres que le despiertan, por lo demás, la misma desconfianza que caracteriza a esa clase que, por su seguridad, acaba de sancionar la ley de residencia. En este sentido, risa y temor resultan inescindibles. Me río de ese "hombre-carbono" que por su misma capacidad infinitesimal para vincularse, deviene, en cierto contexto, infinitamente atemorizante. "Una cierta tendencia asociativa duplica sus fuerzas. En virtud de la ley por la cual los semejantes buscan á los semejantes, todo defensivo se siente atraído por su homónimo cefálico. De ahí procede ese género de epidemicidad de la insignificancia intelectual que suele plasmar, como diría el inolvidable Estrada, sobre la sociedad en ciertas épocas de calamitosa pobreza." ${ }^{93}$

La tensión entre risa y temor circunscribe el espacio de la epidemia, y ella resulta la constatación escandalosa de un mundo que se derrumba. En ese desplome se impone la nueva idolatría, culto procaz del "burgués aureus”, que reduce la vida a una lucha por el dinero y la ciudad señorial a la ciudad fenicia. "Su inocuidad amorfa se adapta con docilidad, y en su virtud transformativa está el éxito; como es inocuo, es fácil darle el matiz de las circunstancias; como no tiene ideales orientaciones, no es difícil fijarle el timón en alguna determinada por sus bajas necesidades, satisfechas sin violencia y sin los peligros y aventuras á que es tan ocasionado el talento."94 El desmoronamiento de lo establecido es caldo tibio y fértil en el que se estimula esa simulación que es el provecho de los "batracios oportunistas". La ciudadela cosmopolita reviste una estética ecléctica y kitsch en el que oropel quiere pasar por oro y en el que las costuras agrupan, bajo la forma del pastiche, los fragmentos heterogéneos. Una retahíla de personajes son llevados a escena para solicitarles su gracia. "En la paleontología social, el guarango representaría uno de esos vertebrados que en épocas remotas buscarán con curiosidad los sociologistas del provenir, para establecer el encadenamiento de los tipos sucesivos de nuestra evolución. Es un invertido del arte, y se parece a los invertidos del instinto sexual que revelan su potencia dudosa por una

\footnotetext{
${ }^{93}$ Ramos Mejía, José María: Los simuladores del talento en las luchas por la personalidad y la vida, p. 34.

${ }^{94}$ Ibid., p. 38.
} 
manifestación atrabiliaria de los apetitos." 95 Si bien ha recibido el néctar de la instrucción, ésta es sólo una pátina superficial que es vencida con facilidad ante la más mínima presión ejercida, entonces se deja exhibir su auténtica epidermis de "indigente del buen gusto". "Por eso, aun cuando le veáis médico, abogado, ingeniero o periodista, le sentiréis a la legua ese olorcillo picante al establo y al Asilo del guarango cuadrado, de los pies a la cabeza. Le veréis insinuarse en la mejor sociedad, ser socio de los mejores centros, miembro de asociaciones selectas y resistir como un héroe al cepillo; le veréis hacer esfuerzos para reformarse y se reformará, a veces; pero cuando menos lo esperéis, saltará inesperadamente la recalcitrante estructura que necesita un par de generaciones para dejar la larva que va adherida a la primera." ${ }^{96}$ La simulación se ejercita en la simultaneidad de tiempos heterogéneos. Detrás de la reforma reciente la "larva golosa" aún se regodea, y finalmente se expone, en los ósculos de la imagen presente, con todo su anacronismo horrible e inhumano.

El titeo que, como más allá de la causerie, es en su origen un ritual entre pares, poco a poco va ampliando su dominio hacia la exterioridad, movimiento que acompaña la mixtura propia de ese cosmopolitismo tan amenazante. En Ramos Mejía, el descenso al inframundo bestial va acompañado de una relajación en los modos del titeo cuyo placer es atributo mismo de la degradación y que deviene, por ello en tomada de pelo. La tomada de pelo es un titeo ya en descomposición, pues trasciende las puertas del recinto honorable para abrirse paso por la toldería vulgar. Es el ejercicio de señores que se ensañan con aquellos que son de un nivel inferior. Liberan por eso mismo su virulencia contenida en la jocosidad por el escarnio. En este sentido, la tomada de pelo se inscribe en "un peculiar movimiento de arriba hacia abajo". 97

En esta cadena imaginaria de la disgregación, el canalla resulta el sustituto descendente del guarango. "El canalla es el guarango que ha trepado por la escalera del buen vestir o del dinero, pero con el alma todavía llena de atavismos, en quién, podríamos decirlo abusando de la anatomía sui generis de los legos, el hígado, por anomalías de la misma especie, derrama sus venenos sobre el corazón en vez de arrojarlos al intestino. ${ }^{98}$ Esta cadena se prolonga en el huaso y en el compadre como

\footnotetext{
${ }^{95}$ Ramos Mejía, José María: Las multitudes argentinas, p. 218.

${ }^{96}$ Ibid., p. 219.

97 Viñas, David: Crisis de la ciudad señorial, p. 99.

${ }^{98}$ Ramos Mejía, José María: Las multitudes argentinas, p. 220.
} 
límite de su deformidad. "El huaso es un guarango de especie más grotesca; piel moral de paquidermo, que araña con su áspero roce, y del cual, por obra del medio, sale el compadre, que es un huaso espiritual morigerado por el contacto urbano y la constante sujeción al trabajo callejero, que lo pone en contacto diario con todas las clases."99

La lista prosigue casi indefinidamente, ya que si el titeado se define por su "defecto o carencia que lo pone en inferioridad de condiciones", ocupa, por eso mismo, un lugar estructural en este ritual escabroso de la broma y la simulación. El sitio de lo segregado, de lo otro, lo diferente que se rechaza y que se busca tener a raya. Por eso lo suculento de la lista, pues si no hubiese diferencia se tendrían que inventar. Ya que el fin es otro que el mero conocimiento sociológico. Por el contrario, lo que Ramos Mejía como exponente de su clase despliega, es una vergonzante e inconfesable estrategia defensiva en la que el desinterés gnoseológico encubre o censura un gran espectáculo sacrificial. ${ }^{100}$ Por mediación de este sacrificio se busca exorcizar el pánico en un instante de risa compulsiva y maníaca, fijar los significantes a través de la inmolación de una víctima, cuya sangre redime en el momento de crisis la supervivencia ruinosa de ese mundo que se hunde. La víctima propiciatoria cumple así una doble función. En primer lugar, expulsa lo intocable, manteniendo el fantasma de pureza de un nosotros que suspira por sentirse liberado de lo infecto y escatológico. En segundo lugar, le sirve a ese nosotros para suturar sus heridas y así reconfigurar sus lazos de solidaridad en un destino común y homogéneo. "De alguna manera, pues, la presencia del titeado equilibra por descarga las tensiones del grupo. O lo que viene a ser lo mismo: la existencia del titeado es necesaria para la sobrevivencia y equilibrio interno del grupo." ${ }^{101}$ Ese es el juego latente a los escritos de Ramos Mejía. La marca retórica en la que habita su grandeza literaria y su patetismo elitista. Es una voz que persigue la

\footnotetext{
${ }^{99}$ Ibid., p. 221.

${ }^{100}$ Defensiva pues resulta incuestionablemente un juego mismo de la simulación que como tal, pretende disimularse. En este sentido, Ingenieros describe al simulador fumista. "Hemos conocido algunos simuladores fumistas. Sujetos mentalmente superiores, hiperestésicos e hiperactivos a la vez, exuberantes de la vida y de la alegría, su ocupación característica es deleitarse en «tomar el pelo» a los tontivanos, haciendo un verdadero deporte de la fisga; «burla que se hace de una persona, con arte, usando de palabras irónicas o de acciones disimuladas» (...) El objetivo del fumista simulador está en la simulación misma y en el placer intelectual que le reporta realizar su propósito. Es, a menudo, un artista de la simulación: trabaja, apasionadamente, por amor a su arte." Ingenieros, José: La simulación de la locura en la lucha por la vida, pp. 126 - 127.

101 Viñas, David: Crisis de la ciudad señorial, p. 104.
} 
complicidad de un "nosotros", que habla a los pares, y por ello "en virtud de sobreentendidos, historias y valores comunes, queridas y prejuicios compartidos, proyectos y entonaciones y enfermedades secretas" 102 Es, finalmente, un juego decadente, de gasto suntuario del estilo, epígono de un capricho que nace del aburrimiento de aquellos que tienen, en el ocio y el hastío, un legítimo y distintivo derecho de clase.

\section{3. De los simuladores de la locura.}

La motivación de Ingenieros en torno a la simulación es divergente respecto de la de Ramos Mejía, aunque, no por eso, resulta menos inquietante. Comparte con aquel, la denuncia de la apariencia como estrategia defensiva, pero su desasosiego por el transformismo busca saciarse por intermedio de una inquisición que derrama agudeza ante la momentánea indistinción entre locura y criminalidad. La simulación empaña la percepción y habilita, por esa misma borradura, el vínculo estrafalario entre la estrategia del gusano y la del delincuente que se disfraza detrás de un presunto desequilibrio mental. La patología simulada irrumpe como el fantasma de la perversión de la ley, que queda, a partir de la capacidad histriónica del simulador burlada en su mismo dominio normalizador.

Como un signo de la época, Auguste Villiers de L'Isle-Adam explora en un texto esta misma vacancia de la ley ante el problema análogo de la sugestión hipnótica. Un tal Hillairaut, nos dice, fue condenado a trabajos forzados por un intento de homicidio que busca ser disculpado por resultar, el atacante, víctima de sugestión. "Este Hillairaut, a quien los médicos diagnosticaron una afección nerviosa clasificada como histeria patriótica (monomanía a la cuarta potencia, en los límites del iluminismo), tenía predisposición a sufrir inconscientemente la sugestión de cualquiera. El informe añade que la defensa apeló el fallo por ese motivo." ${ }^{103}$ Villiers de L'Isle-Adam lanza una sorna, ácida y escéptica, no sólo sobre la justicia, sino en particular, por el prestigio fantasmagórico de la psiquiatría en tanto que pseudocientífica en ascenso. El dilema es si el crimen está en el acto o en el que lo induce, con el agravante de que en este caso

\footnotetext{
102 Ibid., p. 99.

${ }^{103}$ Villiers de L Tsle-Adam, Auguste, La sugestión ante la ley, en Antología del decadentismo, perversión, neurastenia y anarquía en Francia, 1880 - 1900, Bs. As., ed. Caja Negra. p. 83.
} 
singular, el acto se solapa tras la somnolencia del hipnotismo. Así lo comprende la defensa que rápidamente se mimetiza tras el discurso médico al que parece otorgarle un crédito infinito, que por esa misma prodigalidad debería, como mínimo, llamar la atención. "Dado un cierto individuo con un probado cuadro histérico-nervioso, la Ciencia puede oficialmente Afirmar que cualquier persona dotada tan sólo de una voluntad más firme está en condiciones de inducirlo irresistiblemente, sin dejarle el menor recuerdo ni permitir sospecha alguna, a cometer un acto criminal de la naturaleza que fuere. Pues el sujeto en estado de hipnosis es una especie de absoluta inconsciencia que camina y actúa a ciegas, habiendo olvidado de antemano el acto que va a cometer. Por poco que el sugerente haya calculado las circunstancias en las cuales la idea concebida debe llevarse a cabo, se servirá de «su sujeto» como de un arma segura, capaz de herir a distancia y a hora fija, mecánicamente, sin vacilación, temor ni coraje. Por absurdo o indignante que pueda resultarle el acto en cuestión, lo ejecutará invariablemente." 104

Ingenieros extrema la reputación fraudulenta de la simulación en la lucha por la vida. Pero también entiende que la capacidad para simular es efecto de la complejidad creciente de los medios en el mismo proceso por el que se complejiza la vida como producto de la evolución biológica. "Culmina este desenvolvimiento en la especie humana, que por su estructura cerebral y sus funciones mentales está colocada en el término del phylum más evolucionado de los vertebrados; esa circunstancia hace que en el hombre los medios de lucha por la vida sean más complejos que en los demás animales, pues su inteligencia le ha permitido reforzar los deficientes, suplir los ineficaces e imaginar medios artificiales de aumentar su propia capacidad ofensiva y defensiva. Limitados sus medios físicos de lucha (...) ha perfeccionado casi ilimitadamente sus medios de lucha mediante la mentira y el fraude, la astucia y la simulación." ${ }^{105}$ A diferencia del animal, la simulación es en el hombre un proceso "consiente y voluntario". Es este plus, justamente, aquello que la acerca irreversiblemente al fraude o a la estafa, a una ganancia obtenida por medios deshonrosos, una victoria lograda à rebours del justo proceso de la selección natural. Cabe destacar que esta calificación peyorativa de la simulación, es difícil de justificarse

\footnotetext{
${ }^{104}$ Ibid., p. 84.

${ }^{105}$ Ingenieros, José: La simulación de la locura en la lucha por la vida, pp. 26 - 27.
} 
en virtud de los mismos términos que se sostienen, lucha por la vida y selección natural. Tomados estos últimos al pie de la letra, la simulación debería ser un modo más de la eficacia de un ser singular que asegura su supervivencia. Pero si la simulación es contra natura, es porque "invierte la selección natural". Aquí aparece nuevamente, la función fetichista que ocupa lo biológico en cuanto que código mágico al que se lo pretende como garante último que permita censurar o suprimir el poder demoníaco de lo metafórico y del artificio. A partir de este recurso, estos últimos, acceden a ser juzgados como meras desviaciones, es decir, traslaciones extraviadas que resultan conjurables, una vez que se las retrotrae al origen legítimo (lo biológico) como reservorio último de toda literalidad escondida.

El fraude es una "sanción al uso" que aumenta en virtud del crecimiento de intensidad de la lucha por la vida a partir de la pluralidad de intereses personales que se oponen en una sociedad. El fraude es siempre una lectura del otro, aduladora o despreciativa, que se origina en una lectura anterior de la propia deficiencia a enmascarar. Por eso se sostiene en el "engaño recíproco" como apoteosis carnavalesca que sublima la hostilidad social. Llevado a su hipérbole, una sociedad educada en la simulación universalizada, deviene una "hipocresía generalizada", un juego de simulación y disimulo que se aprende desde niño con el primer fin banal y trivial de la satisfacción un capricho. Una sociedad atestada de farsantes y embusteros, "empuja al individuo a engañar a sus semejantes". "La culpa es de una moral social que tiene sus bases en la mentira; la educación está envenenada por ella; la tolerancia general agrava en cada uno esta triste aptitud de engañar para vivir."106

La simulación de la locura deviene acuciante en este contexto que connota cierta predisposición a caotizar las relaciones. Pues el simular redunda, como siempre, en provecho del simulador, mejorando sus condiciones de lucha por la vida, a la vez que hace disminuir la resistencia del medio a la expansión de su personalidad. Como en el caso del intento de homicidio por sugestión relatado por Villiers de L'Isle-Adam, la simulación de la locura por el criminal, posee un idéntico carácter mordaz y tóxico que crea una vacancia irónica en derredor de la ley. La sugestión y la locura, por "una circunstancia propia de la legislación penal", derogan la responsabilidad del acto y por esa vía, devienen susceptibles de sustraer al delincuente simulador a la imputabilidad

\footnotetext{
${ }^{106}$ Ibid., p. 86.
} 
jurídica. "El delincuente, en su lucha por la vida contra el ambiente jurídico, simula ser alienado para eludir la responsabilidad del acto delictuoso y ser excluido de la pena." 107

Más allá de las diferencias, que las hay y muchas, tanto Ramos Mejía como Ingenieros poseen también ciertas similitudes. Puntos encontrados que preferiblemente se silencian y que consuetudinariamente se conciben como un humus de época. Si en el primero, la motivación es un espanto de clase que se lee en conjunción gloriosa con una risa acalorada que clama por el sacrificio; en el segundo, mucho más gris y mesurado, la crítica sociológica adquiere, ante el proceloso desborde que la simulación imprime a la lucha por la vida, un tinte policíaco que llama al orden y a la "defensa social" por la intermediación de una reforma jurídica. Ya que la simulación de la locura tiene su origen en el criterio jurídico que discreta entre responsabilidad e irresponsabilidad del sujeto ante los actos, se precisa una reforma que la haga nociva para el simulador. "Reemplazando el criterio de la irresponsabilidad del delincuente por la aplicación de la defensa social proporcionalmente a su temibilidad, la simulación de la locura tórnase perjudicial para los simuladores, desapareciendo de la psicología forense."108 Finalmente, no existe más ciego a las propias simulaciones que aquel que se considera exento totalmente de ellas. "Para el común de los hombres, «saber vivir» equivale a «saber simular»; sólo algunos individuos superiores, dotados de especiales condiciones para la lucha por la vida, pueden imponer su personalidad al ambiente sin someterse a simular para adaptarse. Los hombres, en general, se adaptan tanto mejor al medio en que luchan por la vida cuanto más desarrollada tienen la aptitud para simular." 109 En Ramos Mejía se huele una especie de derecho de clase, que con una petulancia sin pruritos, ejerce descendentemente una crítica mordaz que jamás llega a concebir su propia instancia enunciativa como posiblemente cuestionable. Ingenieros, que no pertenece al mismo sector social, transfiere su escena legitimante desde el apellido a un esteticismo romantizante del "hombre superior", caso que, su obviedad nos exime de demostrarlo, identifica consigo mismo.

\section{Bibliografía:}

\footnotetext{
${ }^{107}$ Ibid., pp. $158-159$.

${ }^{108}$ Ibid., p. 162.

${ }^{109}$ Ibid., p. 86.
} 
Adorno, Theodor W.: El ensayo como forma, en Notas sobre literatura, Obra completa, 11, Madrid, ed. Akal, 2013.

Arendt, Hannah: La condición humana, Bs. As., ed. Paidós, 2011.

Baudelaire, Charles: Moral del juguete, en Salones y otros escritos sobre arte, Madrid, ed. Visor, 1996.

Baudelaire, Charles: Las multitudes, en Pequeños poemas en prosa, Madrid, ed. Cátedra, 2010.

Benjamin, Walter: París, capital del siglo XIX, en El París de Baudelaire, Bs. As., ed. Eterna cadencia, 2012.

Buck-Morss, Susan: Dialéctica de la mirada. Walter Benjamin y el proyecto de los Pasajes, Madrid, ed. Antonio Machado libros, 2001.

Caillois, Roger: El mito y el hombre, México, ed. Fondo de cultura económica, 1998.

Didi-Huberman, George: La invención de la histeria, Charcot y la iconografía de la Salpêtrière, Madrid, ed. Cátedra, 2007.

González, Horacio: El prologuista francés y la locura de los símbolos: el “incidente” Ramos Mejía, en Retórica y locura, Bs. As., ed. Colihue, 2004.

González, Horacio: José María Ramos Mejía: terror, locura y misticismo, estudio preliminar a Las neurosis de los hombres célebres en la historia argentina, estudio preliminar a Ramos Mejía, José María: Las neurosis de los hombres célebres en la historia argentina, Bs. As., ed. Biblioteca nacional, 2013.

Habermas, Jürgen: Teoría y praxis, estudios de filosofía social, Madrid, ed. Tecnos, 2012.

Huysmans, Joris-Karl: a contrapelo, Madrid, ed. Cátedra, 2012.

Iglesias, Claudio: Prólogo e introducción a Antología del decadentismo, perversión, neurastenia y anarquía en Francia, 1880 - 1900, Bs. As., ed. Caja Negra.

Ingenieros, José: Sociología argentina, Bs. As., ed. Losada, 2013.

Ingenieros, José: La locura en la Argentina, Córdoba, ed. Buena vista, 2005. 
Ingenieros, José: La simulación de la locura en la lucha por la vida, Córdoba, ed. Buena vista, 2005.

Jauss, Hans Robert: Las transformaciones de lo moderno. Estudios sobre las etapas de la modernidad estética, Madrid, ed. Antonio Machado libros, 2004.

Kierkegaard, Soren: Sobre el concepto de ironía, en Escritos volumen I, Madrid, ed. Trotta, 2000.

Lukács, Gyorgy: Sobre la esencia y la forma del ensayo, en Qué es el ensayo, Bs. As., ed. El cuenco de plata, 2016.

Nietzsche, Friedrich: Introducción teorética sobre la verdad y la mentira en sentido extramoral, en El libro del filósofo, Madrid, ed. Taurus, 2000.

Ramos Mejía, José María: Las neurosis de los hombres célebres en la historia argentina, Bs. As., ed. Biblioteca nacional, 2013.

Ramos Mejía, José María: Las multitudes argentinas, Rosario, ed. Biblioteca, 1974.

Ramos Mejía, José María: Los simuladores del talento en las luchas por la personalidad y la vida, Bs. As., ed. Félix Lajouane, 1904.

Rousset, Jean: Circe y el pavo real. La literatura del barroco en Francia, Barcelona, ed. Acantilado, 2009.

Sarmiento, Domingo Faustino: Facundo, Bs. As., ed. Terramar, 2007.

Schmitt, Carl: El concepto de lo político, Madrid, ed. Alianza, 2009.

Terán, Oscar: Historia de las ideas en la Argentina, diez lecciones iniciales, 1810 - 1980, Bs. As., ed. Siglo veintiuno, 2008.

Terán, Oscar: Positivismo y nación, Bs. As., ed. Puntosur, 1987.

Vezzetti, Hugo: La locura en la Argentina, Bs. As., ed. Paidós, 1985.

Villiers de L’Isle-Adam, Auguste, La sugestión ante la ley, en Antología del decadentismo, perversión, neurastenia y anarquía en Francia, 1880 - 1900, Bs. As., ed. Caja Negra.

Viñas, David: Crisis de la ciudad señorial, Bs. As., ed. Corregidor, 2004. 